\title{
Los relatos evangélicos de la pasión de Jesús
}

\author{
Orientación teológico - pastoral
}

\section{INTRODUCCION}

Los relatos evangélicos de la pasión se han formado y originariamente tal vez han sido progresivamente redactados entre $y$ por quienes se sentian, ante todo, "testigos de la resurrección". De ahí que resulte un tanto paradójica la insistencia que se hace en ta pasión de Jesús. ¿No hubiera sido mejor dejarla en la penumbra e insistir en los aspectos positivos y agradables de la existencia de Jesús? La fe pascual, empero, no ha conducido a una religión de evasión.

El objeto primario y fundamental de la predicación apostólica y de la primitiva fe cristiana es ciertamente la resurrección de Jesús ${ }^{1}$. Sin embargo, este testimonio sobre la resurrección no excluye, sino que presupone, el hecho de la cruz y de la muerte de Jesús ${ }^{2}$. La gloria de la resurrección no ha hecho olvidar los aspectos dolorosos de la vida de Jesús, antes bien ha inducido a valorar notablemente los aspectos más desconcertantes de la existencia del Salvador. La importancia atribuida a la pasión caracteriza la revelación de Crisio y le da autenticidad divina. El mensaje cristiano no se presenta ni aparece como una construcción mítica, que permita olvidar lo real. En los relatos de la pasión de Jesús Dios se nos manifiesta como aquel que no escamotea las realidades de nuestra existencia por más duras que sean y nos enseña e invita a adherir-

1. Cfr. 1 Cor 15,$14 ; 2$ Cor 4,14; Rom 10,9; 1 Tes 1,10; Gal 1,1; Col 2,12; Ef 1,$20 ; 1$ Pe 1,21; etc.

2. Cfr. 1 Tes $4,14 \mathrm{~s} ; 1$ Cor 15,3ss; Rom 4,24-25; 14,9 ; 2 Cor 13,4 ; frecuentemente en Act: $2,22-26 ; 3,12-26 ; 4,8-12 ; 5,29-32 ; 10,34-43 ; 13,23-31$; etc. 
nos plenamente a ellas ${ }^{3}$. La importancia de los relatos de la pasión de Jesús en los "evangelios canónicos" queda más resaltada con los preanuncios de la misma, puestos en boca de Jesús durante su vida pública ", lo que ha motivado que algún crítico moderno, sin demasiado fundamento, haya definido los evangelios como "narraciones de la pasión con una introducción extensa" ".

Los relatos de la pasión de Jesús difieren bastante del resto del "evangelio", especialmente en los sinópticos. Frente a los episodios de la vida pública de Jesús, que fácilmente se pueden desligar unos de otros, la pasión forma un conjunto más coherente e intimamente articulado. Esto hace suponer que desde el principio los relatos de la pasión han sido objeto de una atención especial y han sido considerados como un todo orgánico. La comparación de los sinóṕtíicos con el cuarto evangelio confirma más esta suposición. Aunque el evangelio de Juan difiere considerablemente de los sinópticos, en los relatos de la pasión de Jesús coinciden notablemente, tanto en la elección de los episodios como en el orden general de la narración, sobre todo a partir del prendimiento de Jesús. Esto es indicio de que en la tradición de la Iglesia primitiva se formó muy pronto un relato o esquema general de la pasión de Jesús, que comenzaba con el prendimiento. Se discute entre los críticos si el primer relato escrito debe atribuirse a Marcos o preexistía ya a la redacción de este evangelio y fue usado por él ${ }^{6}$. La mayor parte afirman su preexistencia e incluso distinguen diversos estadios de su redacción?.

Tal esquema general, en el que coinciden todos los evangelistas, se puede estructurar así: prendimiento, proceso judío y romano, ejecución por el suplicio de la cruz y sepultura de Jesús. Con el tiempo esta narración fue ampliándose, conforme a un esquema

3. Cfr. A. VAnhoye, "Structure et théologie des récits de la Passion dans les évangiles synoptiques", en Nouv Rev Theol 89 (1967) 135-136.

4. Cfr. Mc 8, 31-33; 9, 30-32; 10, 32-34 y par.

5. M. KAEHLER, Der sogennante historische Jesu und der geschichtliche, biblische Christus (München 1953) 60 nota.

6. Cfr. J. SchreIBER, Die Markuspassion. Wege zur Erforschung der Leidensgeschichte, Hamburg 1969; E. LINNEMANN, Studien zur Passionsgeschichte (Göttingen 1970) 54-68; G. ScHNErDER, "Das Problem einer vorkanonischen Passionsgeschichte", en Bibl Zeit 16 (1972) 224-244.

7. Cfr. V. TAYLOR, The Gospel according to St. Mark (London 1959) 653-664; G. Schille, "Das Leiden des Herrn", en Zeit Theol Kir 52 (1955) 161-205; X. LEON-DUFOUR, "Passion", en DBS VI, col. 1424-1427; D. DORMEYER, Die Passion Jesu als Verhaltensmodell, Münster 1972; G. SchNeIDER, Die Passion Jesu nach arei älteren Evangelien (München 1973) 13-19; L. SCHENKE, Der gekreuzigte Christus, Stuttgart 1974. 
más o menos firme y estereotipado, que comprendia otros relatos como preámbulos a la pasión. De ahí que todos los evangelistas narren la entrada solemne de Jesús en Jerusalén, la conspiración de los judíos contra El, la unción en Betania (excepto Lc), la última cena en la que Jesús predice la traición de Judas y el escándalo de los discípulos, la visita de Jesús al huerto de los Olivos y agonía de Jesús. Sin embargo, el orden de estos relatos es en gran parte diferente -en In la conspiración de los judios y la unción en Betania se sitúan antes de la entrada triunfal en Jerusalén-y en su contexto se insertan otros relatos de acontecimientos, controversias o discursos de Jesús, que denotan una composición más sistemática que histórica.

Los distintos grupos apostólicos completaron más tarde de modo diverso el esquema general, según las fuentes particulares de que disponian y las necesidades o situación ambiental de aquellos a quienes el evangelio iba destinado. No puede olvidarse que, aunque se trate de una verdadera narración histórica, está condicionada más o menos por la situación o contexto humano en que nace y se desarrolla. Se trata, pues, de una narración histórico-religiosa, dirigida especialmente a la comunidad de creyentes, atraída hacia la contemplación del misterio de la cruz, como obra divina misteriosa y llena de significado. Porque los relatos de la pasión de Jesús no son una referencia puramente biográfica, ni una narración polémica contra los enemigos de Jesús, ni una defensa apologética de la inocencia de Jesús, ni una exhortación moral, aunque contengan muchos elementos que resalten lo inicuo de la muerte de Jesús o proclamen su inocencia o presenten a Jesús como el ejemplo y modelo a imitar ${ }^{8}$. Como proclamación del mensaje salvífico aportado por y en la persona de Jesús, son eminentemente cristológicos, descubriendo el contenido teológico de su persona y obra y la significación religiosa que sus sufrimientos y pasión tienen para el creyente ${ }^{9}$.

8. Cfr. A. VANhoye, De narrationibus passionis Christi in evangeliis synopticis (ad usum auditorum), Roma 1970, 30-34.

9. Cfr. P. Vielhader, "Zu W. Andersen", en Ev Theol 12 (1952-53) 481-484; K. H. SCHELKL, Die Passion Jesu in der Verküdigung des Neuen Testaments (Heidelberg 1949) 17-51; X. Leon-Dufour, "Mt et Mc dans le récit de la Passion", en Biblica 40 (1959) 648-696; S. ScHulz, Die Stunde der Botschaft (Hamburg 1967) 157-234; A. DESCAMPS, "Redaction et christologie dans le récit matthéen de la Passion", en L'Évangile selon Matthieu (Gembloux 1972) 359-415, esp. 410-412; H. Conzelmann, "Historie und Theologie in den synoptischen Passionsberichten", en Zur Bedeutung des Todes Jesu (Güttersloh 1967) 35-53 (traducido en Interp 24, 1970, 178-197); F. JANSSEN, "Die synoptische Passionsgeschichte. Ihre Theologische Konzeption und literarische Komposition", en Bib Leb 14 (1973) 40-57; H. KESSLER, Die theologische Bedeutung des Todes Jesu, Düsseldorf 1971. 
Junto a esta orientación y valores histórico-religiosos generales, cada evangelista, como verdadero autor que propone de modo vivo y personal los hechos que motivan la fe, imprime a su narración caracteristicas particulares ${ }^{10}$. Marcos, conforme a su manera de expresarse, narra los hechos en su cruda realidad, a veces escandalosa (=narración kerigmático-paradójica), sin atenuar el escándalo de la cruz en la que de forma misteriosa y contra todo pronóstico se da la revelación de Jesús como Mesías e Hijo de Dios ${ }^{11}$. Mateo, con estilo claro, respetuoso e hierático, ofrece una narración cristológico-eclesial, insistiendo en la relación de los discípulos con Jesús y explicando el misterio de la cruz en la Igiesia y con relación a la Iglesia, destacando la ruptura entre Israel y su Mesías, como ocasión de la constitución de la Iglesia en cuanto pueblo de Dios de la nueva alianza ${ }^{12}$. La narración de Lucas, aparte de su orientación general geográfico-teológica centrada en Jerusalén ${ }^{13}$, tiene un matiz parenético personal, interesándose especialmente por la relación y adhesión personal del discípulo con Cristo y por medio de Cristo con Dios. De ahí su sobriedad en la descripción de las afrentas a Jesús y su insistencia en que es inocente ${ }^{14}$. Juan ofrece una pasión glorificante, destacando frecuente-

10. Cfr. K. H. SchelkLe, 1. c.; X. LeON-Dufour, "Passion", en DBS VI, col. 1473-1479; W. HillmanN, Aufbau und Deutung der synoptischen Leidensgeschichte, Freibu"g 1941; M. LACONI, "Le caratteristiche del racconto della Passione nei singoli Evangelisti", en Riv Asc Mist 13 (1968) 149-164; A. VANHOYE, "Structure et théologie...", 137-139; J. RIEDL, "Die evangelische Leidensgeschichte und ihre theologische Aussage", en Bib Lit 41 (1968) 70-111.

11. Cfr. J. SCHREIBER, Theologie des Vertrauens. Eine redaktionsgeschichtliche Untersuchung des Markusevangelium (Hamburg 1967) 235 ss; T. A. BURkILL, "St. Mark's Philosophy of the Passion", en Nov Test 2 (1957-58) 245-271, esp. $245 \mathrm{~s}$.

12. Cfr. N. A. DAHL, "Die Passionsgeschichte bei Matthäus", en New Test Stud 2 (1955-56) 28; G. STRECKER, Der Weg der Gerechtigkeit (Göttingen 1966) $117 \mathrm{~s}$; W. Trulling, "Die Passionsbericht nach Matthäus", en Am Tisch des Wortes 9 (1965) 33-44; K. M. FISCHER, "Redaktionsgeschichtliche Bemerkungen zur Passionsgeschichte des Matthäus", en Theologische Versuche 2 (B-Ost 1970) 109128; D. P. SENIOR, The Passion Narrative according to Matthew. A Redactional Study (Leuven 1975) 337-338.

13. Cfr. H. ConzenmanN, Die Mitte der Zeit. Studien zur Theologie des Lukas, Tübingen 1960; A. GEORGE, "Tradition et rédaction chez Luc. La construction du troisiéme Evangile", en Ephem Theol Lovan 43 (1967) 100-129; K. LoENING, "Lucas, teólogo de la historia de la salvación concluida por Dios", en Forma y propósito del Nuevo Testamento (Barcelona 1973) 236-268; G. SCHNEIDER, Verleugnung, Verspottung und Verhör Jesu nach Lukas 22, 54-71 (München 1969) 196-203, 207-210.

14. Cfr. A. Vanhoye, De narrationibus passionis..., 39-41; M. GalizzI, "La Passione secondo Luca", Parola di Vita 16 (1971) 444-460; G. SCHNEIDER, Verleugnung..., 169, 187-190.

Según A. George ("Le sens de la mort de Jésus pour Luc", en Rev Bibl 80, 1972, 186-217), opinión recogida por A. FeuIllet ("Luc et l'agonie de Gethsémani: 
mente en sus relatos la vitalidad trascendente y la plena autonomía de Jesús ante sus enemigos, conforme a la imagen gloriosa del Cristo juánico, partícipe ya en su vida terrestre de la gloria del Padre, que se manifiesta en todas y cada una de sus acciones y discursos ${ }^{15}$.

Lc XXII: $39-46$ ", en New Test Stud 22, 1976, 397-417), en la pasión lucana domina la idea de mostrar en la muerte de Jesús al mártir por excelencia, que funda el nuevo pueblo de Dios.

15. Cfr. H. DoDd, The Interpretation of the Fourth Gospel (Cambridge 1960) 423 ss; W. THuEsING, Die Erhöhung und Verherrlichung Jesu im Johannesevangelium, Münster 1960; A. DAUER, Die Passionsgeschichte im Johannesevangelium (ünchen 1972) 237 ss; G. Tosatro, "La Passione di Cristo in S. Giovanni", en Parole di Vita 15 (1970) 377-388; I. DE LA POTTERIE, "La Passion selon Jean, Jn 18, 1-19, 42" en Assamblée du Seigneur 2,21 (1969) 21-34; E. HaENCHEN, "Historie und Geschichte in den johanneischen Passionbericht", en Zur Bedeutung des Todes Jesu (Gütersloh 1967) 55-78; G. RICHTER, "Die Deutung des Kreuzestodes Jesu in der Leidensgeschichte des Johannesevangelium (Jo 13-19)", en Bib Leb 9 (1968) 21-36; O. TரÑI, "Pasión y muerte de Jesús en el cuarto evangelio: papel y significación", en Rev Catal Teol 1 (1976) 393-419. 


\title{
Agonía de Jesús en Gethsemanl ${ }^{16}$
}

\author{
(Mc 14, 32-42; Mt 26, 36-46; Lc 22, 39-46) \\ (cfr. Jn 18,1.11; 12, 27-29)
}

El primer episodio sobre el que se centra nuestra atención es la agonía de Jesús en Gethsemaní, narrada por los tres sinóplicos. Jn no la relata, ya que encuentra difícil la incorporación de esta escena en su evangelio, dado que en él todos los relatos de la pasión, desde el principio hasta el final, son representados como el triunfo de Jesús, su exaltación, por lo que son omitidos los episodios de este tipo. Sin embargo, conoce la retirada de Jesús al huerto con la que inicia el relato del prendimiento, alude al cáliz que ha de beber $y$, en otro contexto, aparecen curiosamente varios términos y expresiones análogos a la escena sinóptica de la agonía de Jesús. En Jn 12, 23-28 Jesús es presentado como desgarrado por emociones conflictivas, aunque en un retrato sereno y sublime del Maestro tal como gusta pintarle el cuarto evangelio ${ }^{17}$.

16. Cfr. M. Dibelidus, "Gethsemane", en Botschaft und Geschichte: 1 (Tü. bingen 1953) 258-271; K. H. KuHN, "Jesus in Gethsemane", en Ev Theol 12 (195253) 260-285; Y. B. TremeL, "Agonie de Jésus", en Lum Vie 68 (1964) 79-103; T. Lescow, "Jesus in Gethsemane", en Evang Theol 26 (1968) 141-159; G. Gamba, "Agonia di Gesú", en Riv Bibl 16 (1968) 159-166; R. S. Barbour, "Gethsemane in the Tradition of the Passion", en New Test Stud 16 (1970) 231-251; M. GaLIz$\mathrm{zI}$, Gesú nel Getsemani, Roma 1972: amplio y profundo estudio redaccionalcrítico-literario, con abundantísima bibliografía y examen crítico de estudios anteriores sobre el tema; E. LoHSE, La storia della passione e morte ai Gesú Cristo (Brescia 1975) 67-80; J. WarReN Hollerang, The Synoptic Gethsemane. A Critical Study, Roma 1973; W. H. KELBER, "Mark 14, 32-42; Gethsemane. Passion, Christology and Discipleship Failure", en Zeit Neut Wiss 63 (1972) 166-187; "The Hour of the Son of Man and the Temptation of the Disciples", en The Passion in Mark, 41-60; W. MoHN, "Gethsemane (Mk 14, 32-42)", en Zeit Neut Wiss 64 (1973) 194-208.

17. Cfr. R, E. BRown, "Incidents that are in the synoptic Gospels, but dispersed in St. John (I. The Agony in the Garden...)", en Cath Bibl Quart 23 (1961) 143-148; B. P. RoBrnson, "Gethsemane: The Synoptic and the Johannine Viewpoints", en Church Quart Rev 167 (1966) 4-11; M. GalizzI, o. c., 210222 ; R. SchNaCKENBURG, Das Johannesevangelium: III Teil (Freiburg 1975) 249. 
Mc nos ofrece el bosquejo esencial de la escena y, en conformidad con su estilo vivaz, coloquial y arcaico, cuenta los hechos en su cruda realidad. Mt en conjunto concuerda casi literalmente con Mc. Preocupado, sin embargo, por expresarse bien, mantiene en su narración un tono más igual, digno y claro teniendo mayor consideración con Jesús y sus discipulos. Lc procede con más libertad: abrevia y simplifica considerablemente el texto de $\mathrm{Mc}$, suprimiendo $o$ atenuando todos los rasgos que pudieran ser entendidos como una debilidad humana en Jesús. Presenta, además, el dato de la aparición del ángel, que viene a confortar a Jesús, y el sudor de sangre ${ }^{18}$.

Para facilitar la inteligencia y comprensión del contenido de dichos relatos, aunque sin pretender prejuzgar su secuencia temporal, puede distribuirse el episodio en las escenas siguientes:

\section{Llega Jesús con sus discípulos al monte de los Olivos (Mc 14, 32a; Mt 26, 36a; LC 22, 39-40a; Jn 18,1):}

Aunque la estructuración de los acontecimientos precedentes sea diferente (Mc y Mt contra Lc y Jn), lo que motiva la distinta introducción redaccional en cada evangelista, todos afirman el hecho de la llegada y presencia de Jesús y sus discípulos en el monte de los Olivos. Mc y Mt concretizan más el lugar, denominándolo Gethsemani, sin duda por tratarse de una propiedad en la que existía un lagar para prensar aceitunas y extraer el aceite, a causa de los numerosos y frondosos olivos que allí crecían. Jn habla de un huerto situado al otro lado del torrente Cedrón, que topográficamente coincide con la propiedad anterior ${ }^{19}$.

Debía ser este huerto propiedad de algún discípulo o amigo de Jesús, ya que Jesús, según costumbre (Lc; cf. 21,37), se reunía alli muchas veces con sus discipulos ( $\mathrm{Jn} 18,2$ ), lo que excluye la suposición de que Jesús se hubiera retirado allí para evitar o retrasar su prendimiento.

Sin hacer distinciones entre Jesús y sus discípulos, Mc dice que vienen a una propiedad. Mt, sin embargo, por deferencia y respeto y como centrando su interés en el sujeto principal de los acon-

18. Cfr. A. FeUtLLet, l. c.; E. LiNNEMANN, o. c., 34-40.

19. Subrayamos el texto bíblico y especificamos a continuación su pertenencia para facilitar al lector la comprensión de las particularidades de cada evangelio 
tecimientos, pone de relieve la persona de Jesús: va Jesús con ellos... ${ }^{20}$. Lc, conforme a su perspectiva parenética personal, afirma que los discipulos le siguieron ${ }^{21}$. Jn destaca el grupo de Jesús con sus discípulos en contraposición al de Judas y sus acompañantes.

\section{Jesús se retira a orar y entra en agonía}

(Mc 14, 32b-35a; Mt 26, 36b-39a; Lc 22, 40-41):

Una vez llegado a este lugar (LC), Jesús muestra sus deseos de estar solo y retirarse a orar. Dice a sus discipulos: sentáos aqui, mientras voy a orar alli (Mc-Mt). Frecuentemente durante su vida pública Jesús se ha retirado a orar en soledad ${ }^{2}$. Esta vez, sin embargo, quiere que no se alejen demasiado y le acompañen en la oración sus discípulos (Lc) y, más concretamente, sus tres intimos (toma consigo a Pedro, Santiago, y Juan: Mc-Mt) ${ }^{23}$, para que sean testigos de su lucha interior, que va a dar comienzo, como lo fueron anteriormente de su gloria ${ }^{24}$ y poder taumatúrgico.

No parece ajena a la intención de Mc y Mt la idea de que Jesús en medio de su angustia desea buscar cierto consuelo en la cercanía de los tres preferidos, que desgraciadamente defraudarán sus esperanzas. Es un aspecto más de sus rasgos humanos. Lc, sin embargo, presentando la tristeza y angustia de Jesús según una tradición y orientación más personal, describe a Jesús afrontando El solo su agonía sin necesitar del consuelo de los tres discipulos. Al contrario, omitiendo también las venidas y quejas de Jesús a sus discipulos, así como las palabras sobre su angustia y tristeza de muerte, presenta a Jesús confortando a sus discípulos contra la tentación ya al comienzo de la escena con la exhortación orad para no caer en la tentación y no volviendo a ellos sino al final, repitiendo de nuevo su amonestación.

Estando a solas, con los tres íntimos más cerca, comenzó a experimentar una terrible angustia, que continuará en trágico cres-

20. Cfr. P. Benoit, Pasión y Resurrección del Señor (Madrid 1971) 26; T. LESCOW, 1. c., 153 ; D. P. SENIOR, o. c., 100-101.

21. El tema del "discipulado" es también peculiar de Mt (cfr. E. KLosterManN, Das Matthäusevangelium, Tübingen 1938, 211; W. Grundmann, Das Evangelium nach Matthäus, Berlin 1971, 539). Sin embargo, en los relatos de la pasión el tema del "seguimiento" es más expresivo en Lc.

22. Cfr. Mc 1,$35 ; 6,46$ y par.; Lc 3,$21 ; 6,12 ; 9,28$.

23. Mt escribe: a los dos hijos del Zebedeo, sin especificar sus nombres.

24. Cfr. Mc 9, 2-8 y par. 
cendo hasta llegar a la fase final - tal vez la que Lc recoge- en la que Jesús llega a experimentar "agonía". Ha llegado la hora de la pasión, largo tiempo antes predicha y presente ya de continuo en la mente de Jesús, a tenor del contenido evangélico. El lo sabe claramente y este conocimiento le produce una angustia y conmoción interior profundas.

Mc califica esta angustia de Jesús con la cruda expresión de sentir pavor y angustiarse y Mt con otra menos fuerte y más correcta: sentir tristeza y angustiarse. Ambas expresan muy bien el sentimiento de una angustia tremenda, que produce un profundo tedio y hastío, un estado de profundísima tristeza acompañada de sobresalto, pavor y espanto. Sin embargo, por el contexto, es preciso reconocer que es una agonía de temor y horror ante el futuro inmediato, pero no de desesperación.

Esta situación psicológica le invita a Jesús a comunicárselo a sus tres íntimos con unas palabras, de profundas reminiscencias biblicas ${ }^{25}$, que expresan el mayor grado de tristeza y congoja posible: mi alma está triste hasta el punto de morir ${ }^{26}$. Tras esta manifestación de su terrible angustia, les exhorta: quedáos aqui, junto a mí, y velad conmigo (Mc-Mt). Exhortación genérica a la vigilancia, que aquí parece tener una motivación psicológica, aunque no excluya sin más la motivación moral, espiritual, como aparece más adelante (v. 38 en Mc; v. 41 en Mt).

Hecha esta recomendación, Jesús se adelanta un poco (Mc$\mathrm{Mt}$ ), como un tiro de piedra (LC), pues, no obstante tener cerca a sus discipulos íntimos, quiere en parte estar solo en su agonia. Entonces -en expresión de Mc-caía por tierra y suplicaba (en imperfecto: acción continua, que se prolonga) ${ }^{27}$, expresión fuerte que Mt atenúa escribiendo cayó sobre su rostro, sugiriendo la idea de prosternación, de adoración y plegaria ${ }^{28}$. Lc, aun más respetuoso, describe a Jesús puesto de rodillas e insistiendo en la oración (=oraba, en imperfecto).

25. Cfr. Sal 42,6 ; Jon $4,9 b$; Sir 51,6 .

26. Según A. E. Thompson ("Our Lord's Prayer in the Garden", en Bibliotheca Sacra 97, 1940, 110-116) esta tristeza sería tan grande que Jesús corría el peligro de morir debido a ella. Sin embargo, debe entenderse en el sentido explicado.

27. El sentido de angustia contenido en esta expresión se encuentra también en Jos 7,$6 ; 1$ Sam 28,20.

28. Cfr. M. J. LAGRANGE, Evangile selon Saint Matthieu (Paris 1923) 500; E. LOHMEYER, Das Evangelium des Matthäus (Göttingen 1963) 361. 
Los evangelistas repetidamente hablan de la oración de Jesús, pero sólo en esta ocasión nos dan cuenta de su postura corporal. El estado de supremo abatimiento en que se hallaba y la descripción del pavor que acompañaba a su oración se trasluce en la manera de orar, recogida por Mc y atenuada por Mt y Lc. Son tres maneras de contemplar el misterio de la naturaleza humana de Jesús en su abatimiento y angustia, que mutuamente se enriquecen ${ }^{29}$.

\section{Plegaria de Jesús al Padre}

(Mc 14, 35-36; Mt 26,39; LC 22,42; Jn 12, 27-28a):

Los tres sinópticos transmiten la oración de Jesús, de contenido sustancialmente idéntico, aunque con ligeras variantes modales.

Mc enuncia la plegaria dos veces con fórmulas casi idénticas, que derivan de dos tradiciones anteriores combinadas por el evangelista. Una en estilo indirecto: (para) que a ser posible pasara de El aquella hora. Otra en estilo directo: ¡Abbá, Padre!, todo es posible para ti; aparta de mi este cáliz, pero no se haga lo que yo quiero, sino lo que (quieres) tú. Tanto la "hora" como el "cáliz" se refieren evidentemente al momento escogido por Dios para el acontecimiento de la pasión y muerte de Jesús ${ }^{30}$.

Mt fusiona en una sola las dos fórmulas marcianas, como si se tratara de una repetición anormal: ¡Padre mio!, si es posible que pase de mi este cáliz, pero no sea como yo quiero, sino como (quieres) tú ${ }^{31}$. La fórmula lucana, que filológicamente acusa más la voluntad firme de una determinación práctica del Padre, es más corta que la de Mc, pero sustancialmente idéntica a la de Mc-Mt: ¡Padre!, si quieres, aparta de mí este cáliz, pero no se haga mi voluntad, sino la tuya.

En el cuarto evangelio, después de la entrada triunfal en Jerusalén, Jesús, en respuesta a la demanda de unos griegos, anun-

29. Los evangelistas no especifican los motivos o causas de esta angustia. Sobre el tema cfr. P. Bonnetain, "La cause de l'agonie de Nôtre Seigneur", en Rev A polog 50 (1, 1930) 681-690; M. Galizzi, o. c., 73-79; G. Segalla, "La voluntà del Figlio e del Padre nella tradizione sinottica", en Riv Bibl 12 (1964) 274277.

30. Cfr. Mc 10,38; 'Mt 20,22; Jn 18,11; Mc 14, 23-24 y par. Cfr. además W. H. KELBER, "The Hour of the Son of Man...", 44.

31. Cfr. J. Rocre, "Que ta volonté soit faite (Mt 26,42)", en Vie Spir 93 (1955) 249-268. 
cia la inminente llegada de la "hora" de su glorificación y la necesidad de pasar por la muerte para conseguirlo $(12,23-25)$. La gravedad de la situación en que se encuentra, al ver llegar la "hora", invade de profunda turbación y angustia su interior. También $\mathrm{El}$, como todos los hombres, se estremece ante la presencia de la muerte. La angustia que experimenta le hace exclamar: ahora mi alma está turbada. Y ¿qué voy a decir? ¿Padre, librame de esta hora? Jesús rechaza inmediatamente la posibilidad de hacer una súplica semejante: Pero isi para esto he Ilegado hasta esta hora!

El escapar a esta hora equivaldría a oponerse a la voluntad del Padre, el cual ha permitido que llegara este momento con la convicción de que lo aceptaría. En el estilo juánico es el mismo pensamiento que la aceptación de la voluntad divina en los sinópticos. Dado que viene del Padre, la única oración posible es: ¡Padre, glorifica tu nombre! Otra cosa cualquiera disonaría en labios del enviado de Dios (cfr. Jn 17,4).

La oración de Jesús al Padre - resumida e interpretada por los evangelistas, puesto que dura cerca de una hora- es una plegaria de suprema ternura, de suprema angustia y de supremo abandono a su voluntad ${ }^{32}$.

Es de suprema ternura por la invocación con que se dirige a Dios. Padre (Mc-Lc) o Padre mio (Mt) es una expresión familiar e infantil, pletórica de confianza y al mismo tiempo un tanto sorprendente, ya que los judios no se atrevían a usarla al dirigirse a Dios. Jesús, en cambio, lo hace en casi todas las oraciones o advocaciones suyas, que han llegado hasta nosotros ${ }^{33}$. Abbá, Padre es la invocación filial por excelencia, que manifiesta el secreto último de la misión de Jesús y comprende nuclearmente su mensaje y afirmación mesiánica ${ }^{34}$.

Es de suprema angustia por lo que pide. Asedia la voluntad de su Padre, a quien todo le es posible, invocando su poder y plan redentor, para que le perdone y retire el terrible cáliz de dolor que le

32. Cfr. M. DE TuYa, Del Cenáculo al Calvario (Salamanca 1962) 301-304.

33. Cfr. Mt 11, 25-26 y par.; Lc 23, 34.46; Jn. 11, 49; etc. La única excepción es Mc 15, 33 y par., en la que le llama "Dios mio", por referirse a la cita escriturística del Sal 22,2.

34. Cfr. W. MICHEL, ;Abbá, Père! La prière du Christ et des chretiens, Roma 1963; J. Carmignac, Recherches sur le "Nôtre Père", (Paris 1969) 268-282; W. MARCHEL, Dieu Père dans le Nouveau Testament (Paris 1966) 31-53; J. JEREMAS, "Abba", en Le message central du Nouveau T'estament (Paris 1966) 9-29; "Sentido del Padre nuestro", en Las palabras de Jesús (Madrid 1970) 139-144. 
aguarda ${ }^{35}$. Y 10 hace a pesar de haber hablado en la última cena del valor salvador de su muerte y de su necesidad para la redención. Libremente permite que su voluntad exprese en un primer momento y movimiento lo que a su naturaleza humana significaba el terrible cáliz de su pasión y muerte, apareciendo así plenamente como hombre, en el desgarramiento interior que siente entre la aceptación y el rechazo del cáliz.

Sin embargo, a este primer movimiento, al que libremente da curso, sigue un segundo momento en el que también libremente acusa su determinación de aceptar el cáliz del dolor. La voluntad humana de Jesús se somete y subordina libremente a la voluntad del Padre, obedeciendo hasta la muerte (cfr. Flp 2,8), en exacta correspondencia con la actitud que habia determinado toda su anterior actividad mesiánica y en consecuencia también con lo que enseñó a sus discipulos a pedir en la oración (cfr. Mt 6,10). Por eso fue también esta plegaria un acto supremo de abandono a la voluntad del Padre.

\section{Retornos a los discípulos y nuevas plegarias de Jesús} (Mc 14, 37- 40; Mt 26, 40-44):

Cerca de una hora, según Mc-Mt, ha durado este primer acto de oración de Jesús. Su inquietud interior le lleva a volverse a sus discipulos a buscar consuelo. Pero los discipulos, entre tanto, se han quedado dormidos. Jesús, pues, no encuentra en su cercanía ningún consuelo por parte de los suyos (¿los tres o todos?) en su extrema angustia (cfr. Sal 69,21). Sus idas y venidas, motivo literario para marcar la progresión del relato ${ }^{36}$, son signo del papel negativo que desempeñan en el caso los discípulos. Traslucen, además, la agitación interior de Jesús, pues, aunque los evangelistas no afirman que El sea tentado, cuando retorna a sus discipulos, es para hablarles de tentación.

Despertándoles y evocando las protestas de fidelidad, que durante el camino le habian hecho, les reconviene con un tierno reproche. En Mc va dirigido primeramente a Pedro (=y dice a $\mathrm{Pe}$ dro: Simón, ¿duermes?, ¿no has podido velar una hora?), mientras en Mt. va dirigido a Pedro, como jefe de la Iglesia o comunidad

35. Cfr. W. C. VAN UnNIK, "Alles ist đir möglich" (Mk 14, 36)", en Verborum Veritas. Festsch. G. SthakLeN (Wuppertal 1970) 27-36.

36. Cfr. W. H. KELLER, "The Hour of the Son of Man...", 47-50, 52-54; L. Schenke, Studien zur Passionsgeschichte des Markus (Würzburg 1971) 532. 
eclesial, pero aplicado a todos los demás $(=y$ dice a Pedro: ino habéis podido velar una hora conmigo?) ${ }^{37}$.

Jesús les avisa de la necesidad de velar y orar, alcanzando asi la protección divina para no entrar en la tentación ${ }^{38}$. Esta exhortación a la vigilancia (que aqui debe ser entendida material y espiritualmente) y a la oración, asi como su motivación (=el espiritu está pronto, pero la carne es débil), son de validez general, pero tienen una significación inmediata para la situación en que los discípulos se encuentran, en peligro de un total desconcierto e infidelidad hacia Jesús. No bastan las fáciles protestas nacidas de una buena voluntad, porque la tremenda prueba que se les avecinaba y su debilidad humana podian hacerles caer. De hecho el escándalo de la cruz comienza ya desde ahora a actuar y hacer presa en ellos con una magnitud y un peso abrumador y terrible.

Dejándoles por segunda vez, vuelve Jesús a su oración, cuyo contenido eran las mismas palabras (Mc), que Mt expresa de nuevo en la fórmula iPadre mio!, si esto no puede pasar sin que yo 10 beba, hágase tu voluntad, con alusión expresa al Padre nuestro (6, 10) ${ }^{32}$. Y mientras la angustia de Jesús dura y continúa su ruego de que le sea retirado el cáliz del dolor, los discipulos no son capaces de resistir al sueño. Jesús vuelve hacia ellos y los encuentra dormidos.

Mc y Mt echan un piadoso velo de disculpa sobre los apóstoles: dormían - dicen- porque sus ojos estaban cargados. Mc, reflejando siempre con su colorido y viveza de estilo la catequesis de Pedro, anota la sorpresa de los discipulos ante esta segunda visita: y no sabian qué responderle. Por último, mientras en Mc solamente se sobreentiende (=viene por tercera vez), Mt menciona también de manera expresa la tercera oración de Jesús: y dejándoles de nuevo, se fue a orar por tercera vez, repitiendo de nuevo las mismas palabras.

37. Cfr. B. Werss, Das Matthäusevangelium (Göttingen 1910) 460; W. HrL.LMaNN, Aufbau und Deutung..., 133; D. P. SENIOR, o. c., 109-110.

38. Cfr. J. Carmignac, "Fais que nous n'entrions pas dans la tentation", en Rev Bibl 72 (1965) 218-226; H. KRUSE, "Pater noster et Passio Christi", en Verb Dom 46 (1968) 3-29.

39. También Mt. en los relatos de la pasión evoca frecuentemente temas o palabras de Jesús ofrecidas anteriormente, presentando ahora a Jesús como el Maestro que enseña con el ejemplo. Cfr. W. C. Allen, A Critical and Exegetical Commentary on the Gospel according to St. Matthew (Edinburg 1912) 280; J. SchNIEWINd, Das Evangelium nach Matthäus (Göttingen 1968) 255; D. P. SENIOR, o. c., 112; P. BENOIT - M. E. BorsMARd, Synopse des quatres évangiles ( $\mathrm{Pa-}$ ris 1965$) 297-300$. 


\section{Aparición del ángel y sudor de sangre \\ (Lc 22, 43-44; cfr. In 12, 28b-29):}

Según Lc, durante la oración de Jesús al Padre, en la que la angustia y tristeza de Jesús continúa subiendo hasta su pleamar de agonía, tienen lugar dos fenómenos especiales: se le apareció un ángel venido del cielo, que le confortaba. Y sumido en angustia, oraba más intensamente; y se hizo su sudor -fenómeno sorprente- como espesas gotas de sangre, que caían sobre la tierra.

Ambos datos han creado un fuerte problema critico ${ }^{40}$, relacionado con su autenticidad, por el hecho de que faltan en diversos "mejores" manuscritos $(B=s . I V ; A=s . V . .$.$) y algunos códices de$ diversas versiones, generalmente posteriores al año 300 y representativos de la influencia egipcia. Esto ha llevado a varios críticos a la conclusión de que tales versículos han sido interpolados posteriormente en el relato lucano y no son originales.

Sin embargo, contra esta dificultad está el hecho de su inserción en otros varios "mejores" manuscritos griegos $(S=s . I V ; D=s$. $\mathrm{VI} . .$. ) y códices de diversas versiones y, sobre todo, la testificación que en favor de su autenticidad presenta el testimonio extrinseco de numerosos escritores y Padres antiguos. Justino, Taciano, Ireneo..., Epifanio (MG 43,73) nos hacen saber que se les suprimió o silenció por el abuso que hacían de ellos diversos herejes para negar o rebajar la divinidad de jesucristo, ya que en ellos aparece la figura de Jesús en un crudo y escandaloso realismo, en toda su debilidad humana. Podía, además, considerarse un difícil problema teológico el hecho de que el mismo Señor, que, según Col 1,16 y Heb 1,4 ss, como creador del universo, está sobre los ángeles, sea aquí confortado por uno de ellos, enviado del cielo, y que la angustia ante el dolor y sufrimientos que le esperan por voluntad del Padre le produzcan aquel sudor. De hecho es más difícil explicar satisfactoriamente su interpolación posterior en el evangelio que su supresión voluntaria. Aún recogiéndolo de la tradición, seguramente nadie hubiese añadido al tercer evangelio un pasaje que servía para rebajar aparentemente la divinidad de Cristo y para crear di-

40. Cfr. A. Harnack, "Probleme in Texte der Leidensgeschichte Jesu", en Sitz.-Ber. der Berliner Akad. der Wissenschaft, (1901), 251-255; L. BRUN, "Engel und Blutschweiss Lk 22,43s", en Zeit Neut Wiss 32 (1933) 265-276; H. AsCHERMANN, "Zum Agoniegebet Jesu Lc 22,43 s", en Theologia Viatorum 5 (1953-54) 143149 ; G. SCHNEIDER, "Engel und Blutschweiss (Lk 22, 43-44)", en Bibl Zeit 20 (1976) $112-116$. 
ficultades a la misma fe de los fieles y obstáculos a la atracción de las masas de infieles ${ }^{4}$.

En favor de la autenticidad lucana hablan también su lenguaje, estilo y contenido ${ }^{42}$. El evangelista insiste mucho en las plegarias de Jesús y en las apariciones de ángeles ${ }^{33}$ y los términos precisos que usa para describir la agonía de Jesús parecen derivar de una persona con conocimientos médicos". El término "agonia", cuyo primer significado fue "lucha deportiva" (los juegos se llamaban "agónes"), significa el estado de una suprema angustia, producto a la vez de ansiedad, temor y tristeza ${ }^{45}$.

Estando en este estado de angustia moral, Jesús oraba insistente y repetidamente, con profunda intensidad, tensión y ardor. $Y$ cuando asi oraba, tuvo un sudor, como gotas o coágulos de sangre, que caían a tierra. Expresiones que destacan la inmensa angustia física de Jesús, esa angustia que los médicos suelen reconocer como señal de una extrema agonía o de temor y pánico tremendo (cfr. casos de fusilamientos en la última guerra mundial). Por otro lado, esta situación, desde el punto de vista teológico, destaca la debilidad y la flaqueza humana de Jesús, pero también pone de relieve el poder del socorro divino, que le fortalece, mostrando asi Lc, conforme a la tradición paulina, cómo la fuerza o el poder de Dios sostiene nuestra debilidad humana ${ }^{46}$.

La misión del ángel era confortar a Jesús. No afirma Lc en qué consistió este consuelo y por qué Dios se sirve de un ángel. Ciertamente esta visita no tenía por objeto poner fin a la agonía de Jesús, al contrario, entonces comienza de lleno la lucha interior y las angustias de muerte con las que aumenta también la insistencia en la oración de Jesús. Este rasgo le parece a Lc de importancia, por mostrarse aquí Jesús como el modelo del mártir o del justo en la tentación, para vencer la cual recibe la fuerza o consuelo de Dios, personificado en la persona del ángel ${ }^{47}$. La violencia de la lucha, que pone en tensión todas las energías de Jesús, provoca

41. Cfr. J. Schmid, El Evangelio según San Lucas (Barcelona (1968) $482 \mathrm{~s}$; M. DE TUYA, o. c., 288-295; W. J. HARRINGTON, El Evangelio según San Lucas (Madrid 1972) 311.

42. Cfr. M. Dibelius, Die Formgeschichte des Evangeliums (Tübingen 1961) $220 \mathrm{~s}$; M. GalizzI, o. c., 193-198; P. BENoIT, o. c., 30-31; J. ERNST, Das Evangelium nach Lukas (Regensburg 1976) 607; G. SCHNEIDER, l. c.

43. Cfr. Lc 1-2; Act 5,$19 ; 12,7$. Véase además nota 22 .

44. Cfr. W. K. HoBAR, The medical language of St. Luke (Dublin 1882) 84.

45. Cfr. M. Galizzi, o. c., 166-184.

46. Cfr. 2 Cor 12,10 ; Flp 4,13 .

47. Cfr. M. Diselius, "La signification religieuse des récits évangeliques de la Passion", en Rev Hist Philos Relig 13 (1933) 38; 
también el efecto fisiológico del sudor como gotas de sangre. Prescindiendo de que LC pretenda que esto último lo tomemos literalmente o como una especie de figura retórica -la experiencia del sudor de sangre parece ser un hecho patológico comprobado en ciertas circunstancias - lo cierto es que no se puede dejar de captar en ello la realidad de la agonía misma.

Un sorprendente paralelismo con el ángel confortador de Lc se encuentra también en $\mathrm{Jn}^{48}$. Como respuesta a la oración de Jesús (Jn 12,28a), resuena entonces una voz del cielo, confirmando que el Padre ha escuchado su oración: Le he glorificado y le glorificaré de nuevo... Y algunos de la gente decian: le ha hablado un ángel. Sin embargo, en Jn Jesús sigue en pie y su llamada a la comprensión del Padre queda reducida a una lucha interior.

\section{Final de la agonía de Jesús}

(Mc 14, 41-42; Mt 26, 45-46; LC 22, 45- 46):

Terminada esta oración agonizante, Jesús se levanta y vuelve hacia sus discipulos (Lc), oración y retorno que en Mc-Mt es la tercera, aunque no aparezca claro si entran en escena todos los apóstoles o sólo los tres preferidos. Por supuesto, Jesús les en. cuentra dormidos. Los discípulos dormidos aparecen en contraste con el Jesús que acaba de superar con éxito la crisis de su espíritu. También Lc trata de discuparles: estaban dormidos por la tristeza. Aunque no dice nada sobre la contemplación del pavor y miedo de Jesús por parte de sus discípulos, sin duda intenta sugerir que ellos habian tenido alguna experiencia. De ahí la tristeza y el desánimo, que les incapacita para la oración y les provoca el sueño ${ }^{49}$.

Los tres sinópticos recogen las palabras que Jesús les dirige. Lc, con orientación marcadamente parenética, pone en boca de Jesús las palabras que anteriormente en Mc y Mt Jesús parece diri-

48. Cfr: E. Osty, "Les points de contact entre le récit de la passion dans saint Luc et dans saint Jean", en Mélanges J. Lebreton (Rev Scienc Rel 39, 1951) 146-154; J. H. BERNARD, A Critical and Exegetical Commentary on the Gospel according to St. John, II (Edinburgh 1958) 435; I. BusE, St. John and the Passión Narratives of St. Matthew and St. Luke", en New Test Stud 7 (1960-61) 6576; C. K. BARRET, The Gospel according to St. John (London 1962) 350, 355.

49. Cfr. K. H. Schelkne, Die Passion Jesu, 18; M. Dibelrus, "Gethsemane", 269. G. Voss entiende la "tristeza" en sentido teológico: "caracteriza la situación de los discípulos en el tiempo entre la partida de Jesús y su retorno como juez glorioso" (Die Christologie der lukanischen Schriften in Grundzügen, Bruges $1965,111 \mathrm{~s})$. 
gir a los tres intimos: ¿cómo estáis dormidos? Levantáos y orad para que no caigáis en la tentación. $Y$ de este modo concluye un tanto abruptamente su relato. Según Mc-Mt, Jesús les reconviene: dormid ya y descansad. Basta ya (o ya está bien). Mirad, ha llegado la hora en que el Hijo del Hombre va a ser entregado en manos de los pecadores. iLevantáos! jvámonos! Ya está aqui el que me entrega.

Estas palabras de Jesús ${ }^{50}$, más que un mandato (dar una orden de dormir a los que estaban dormidos no parece muy lógico ni oportuno), denotan un ligero reproche no falto de ironía en forma imperativa, pero una ironía sin amargura ni burla, como una expresión de conformidad. Jesús está ya totalmente conforme con la voluntad del Padre y mira sin vacilación al momento inmediato de su prendimiento. Ha llegado la "hora" en que, por voluntad divina y por fidelidad a su vocación, va a ser entregado en manos de los pecadores. Jesús se entrega voluntariamente a su destino cruel. Esta aceptación no ha sido posible más que con la plegaria. La tentación de rechazar la "hora", de evitar la cruz, ha sido dominada, superada ${ }^{m}$. Jesús acepta la muerte $y$, en vez de esconderse o huir, se entrega voluntariamente en manos de los pecadores, que no son propiamente los paganos, esto es, los romanos, sino los enemigos de Jesús, cuya acción queda aquí designada como pecado ${ }^{52}$.

Nótese que incluso las ideas finales de la agonía de Jesús según los sinópticos aparecen análogamente en Jn, aunque en otro contexto: llega el príncipe de este mundo... jlevantáos, vámonos de aqui! $(14,30-31)$. Tales analogías literarias obligan a pensar en una cierta evolución en la tradición evangélica al relatar la agonía de Jesús en Gethsemaní.

\section{Conclusión:}

Como ha podido observarse, nos encontramos ante diversas redacciones y tradiciones, aunque paralelas, destinadas a relatar

50. Cfr. T. AARS, "Zu Matth. 26,45 und Marc 14,41" en Zeit Wiss Theol 38 (1895) 378-383.

51. Cfr. C. J. ARMBRUSTER, "The Messianic Significance of the Agony in the Garden", en Scripture 16 (1964) 111-119.

52. Según B. Weiss (o. c., 462), W. Hillmann (o. c., 86 Ss), J. Schiniewind (o. c., 255) y P. Bonnard (Evangelio según San Mateo, Madrid 1976, 574) en McMt el momento en que Jesús es entregado en manos de los pecadores constituiría la "hora" decisiva del drama de la pasión. 
la realidad de un mismo episodio, que sirve de introducción a las grandes escenas de la pasión y muerte de Jesús.

Una tradición, la más antigua, insiste en la presentación teológico-soteriológica de la persona y obra de Jesús, el Hijo del Hombre, que ruega para que, si es posible, la "hora" o el "cáliz" de su pasión pase de largo, pero que lo acepta. Se trata, pues, de un tema estrictamente cristológico. Otra, tal vez un poco posterior o contemporánea, pero nacida en otra circunstancia ambiental, insiste en la aplicación moral o parenética del suceso a los creyentes: como Cristo veló y oró en el momento de su gran prueba, dominando la tentación de rechazar la cruz, los cristianos deben también velar y orar con el Señor para no caer en la tentación, ya que "el espíritu está pronto, pero la carne es débil" ${ }^{53}$. Una tercera presentación, posterior, común a Lc y $\mathrm{Jn}$, insiste en la angustia de Jesús y en el socorro del cielo, presentando asi a Jesús como el modelo del justo en la tentación, reconfortado y ayudado por la fuerza de Dios para vencerla.

Todas estas presentaciones, lejos de contradecirse, se enriquecen y completan mutuamente. Los datos iniciales sobre este suceso, atestiguados por quienes presenciaron la escena, han sido objeto de reflexión y asimilación posterior en la predicación de la primitiva comunidad cristiana, que dedujo de ellos diversas lecciones prácticas, insistiendo sobre todo en la aceptación heroica de Jesús y en su voluntaria entrega. Estas tradiciones han sido recogidas más o menos combinadas por los evangelistas quienes, según su trayectoria doctrinal y las circunstancias ambientales, han insistido en tal o cual aspecto. Gracias a esta diversidad de tradjciones han podido transmitirnos en sus páginas mayor riqueza de contenido. Una cosa parece clara en la evolución de la tradición evangélica: hay una tendencia a atenuar o suprimir los rasgos que pudieran ser entendidos como señal de excesiva debilidad humana en Jesús y a destacar únicamente su entrega a la voluntad del Padre.

Esta diversidad de redacciones y tradiciones con sus mutuas incoherencias (=tres apóstoles íntimos o los Once, repetición de las venidas y plegarias o sólo una continuada..., apóstoles dormidos) hacen susceptible de sospechas la historicidad del relato ${ }^{54}$.

53. Cfr. G. Schille, "Das Leiden des Herrn", 188-191; P. BenOIT, o. c., 3335 ; M. GalrzzI, o. c., 270-275; D. P. SENIOR, o. c., 118.

54. Según T. Boman ("Der Gebet Jesu", en New Test Stud 10, 1963-64, 261273) sería necesario admitir que los sinópticos han confundido dos plegarias de 
Sin embargo, precisamente por su desaveniencia con las predicciones anteriores de la pasión y con la conciencia de Jesús de ser el Siervo de Yahvé, que entrega voluntariamente su vida por todos (cfr. Mc 10,45 y par.) y por el contraste que presenta este Jesús tembloroso y lleno de pánico con el taumaturgo, que revela su poder divino con toda clase de milagros y curaciones, no es imaginable la escena de Gethsemani, que muestra también a los discípulos en una luz poco favorable, como una creación legendaria tardía. Solamente con esto, quedaría asegurada ya su historicidad, aun en el caso de que faltara toda posibilidad de explicar el origen de este relato evangélico.

Desde luego se debe decir que los discípulos dormidos no fueron testigos del suceso. Pero los discípulos no dormian aún, cuando Jesús se vio invadido por el primer momento de su terrible angustia $y$, alejándose un poco de ellos, dio comienzo a su oración. Se impone, pues, la conclusión de que, aunque se den muchos elementos teológico-interpretativos, en el fondo la escena es esencialmente histórica y ha sido vivida por algunos testigos presenciales ${ }^{55}$. ¿Cómo y quién podía, sino, inventar un episodio tan desconcertante para la fe, presentando al Señor de la gloria tembloroso; lleno de pavor y temor, ante la muerte? Si el episodio ha sido relatado, sin duda alguna es porque fue real y verdadero. Como confirmación de ello, es muy interesante el pasaje de $\mathrm{Heb} 5,7$, donde su autor parece hacer alusión directa a la agonía de Jesús en Gethsemaní cuando escribe: "el cual, habiendo ofrecido en los días de su vida mortal ruegos y súplicas con poderoso clamor y lágrimas al que podía liberarle de la muerte, fue escuchado por su actitud reverente..." "ss.

Jesús: una tranquila y rebosante de gozo en Gethsemaní, durante la cual los discípulos dormian, y otra angustiosa en otro lugar. Sin embargo sus razones son poco convincentes.

55. Cfr. M. Galizzi, o. c., 275-287. V. TAylor (o. c., 551) afirma que el relato tiene su origen en Pedro.

56 Cfr. RIssi, "Die Menschlichkeit Jesu nach Hor 5, 7-8", en Theol Zeit (1955) 28-45; T. Lescow, "Jesu in Gethsemane bei Lukas und im Hebräerbrief", en Zeit Neut Wiss 58 (1967) 214-239; M. GalizzI, o. c., 222-236. 


\section{II}

\section{Prendimiento de Jesús ${ }^{57}$}

(Mc 14, 43-52; Mt 26, 47-56; Lc 22, 47-53; Jn 18, 2-12)

El episodio del prendimiento de Jesús en Gethsemaní está relatado dramáticamente por los cuatro evangelistas, pero con un enfoque y secuencia temporal distintos. Los tres sinópticos siguen una línea homogénea, con sus peculiaridades características. De los tres, Lc sigue un orden general más lógico, poniendo de relieve su habilidad como escritor. Mt ofrece más detalles que Mc, une a los hechos las palabras que los iluminan y destaca más claramente el carácter voluntario del prendimiento y pasión de Jesús, empleando al mismo tiempo fórmulas y expresiones más semíticas. Jn, en cambio, conservando algunos puntos de enmarque con los sinópticos, omite el beso de Judas y narra una escena en la que acusa su enfoque teológico: destacar la absoluta majestad y libertad de Jesús, que toma la iniciativa y el dominio sobre sus enemigos.

Del conjunto de los cuatro evangelios pueden distinguirse las siguientes escenas:

\section{Llegada de Judas y adversarios de Jesús a Gethsemaní} (Mc 14,43; Mt 26,47; Lc 22, 47ab; Jn 18, 2-3):

Aunque en todos los evangelios se dan diversas expresiones puramente redaccionales para conectar el episodio con los relatos anteriores, los tres sinópticos coinciden en afirmar que, estando

57. Cfr. E. Linnemand, Studien..., 41-69; J. W. Doeve, "Die Gefangennahme Jesu im Gethsemane", en Stud Evang 1 (1959) 458-480; B. SchwaNz, "Jesus überschreitet den Kiidron (18, 1-11)", en Sein und Sendung 29 (1964) 3-15; G. RICHTER, "Die Gefangennahme Jesu nach dem Johannesevangelium (18, 1-12)", en Bib Leb 10 (1969) 26-39; G. ScHNEIDER, "Die Verhaftung Jesu. Traditionsgeschichte von Mk 14, 43-52", en Zeit Neut Wiss 63 (1972) 188-209; Die Passion Jesu..., 43-55. 
aún Jesús hablando con sus discípulos (en Mc-Mt se refiere al anuncio de la inminente llegada del traidor y su gente, con lo que se destaca la presciencia de Jesús), llegó de repente Judas, uno de los Doce, a quien Lc con cierto desprecio designa "el Ilamado Judas". Venía acompañado de un grupo o multitud a la que precedia, como guía (cfr. Act 1,16) que conduce a los que no conocen el camino ni el lugar. Porque, conforme al relato de LC-Jn, de entre todos los que venian a prender a Jesús, sólo Judas conocía el sitio donde se encontraba Jesús, porque Jesús se reunía alli muchas veces con sus discipulos ${ }^{58}$.

Todos los evangelistas coinciden en colocar a Judas a la cabeza de la turba que va a arrestar a Jesús. Incluso el cuarto evangelio, que no habla antes de un arreglo previo entre Judas y los enemigos de Jesús, destaca e insiste en la persona de Judas con su grupo, pues representa a Satanás y al poder de las tinieblas, en contraposición a Jesús y su grupo. Este matiz adquiere en Lc la persona de Judas, en el que había entrado Satanás $(22,3)$ y quien personifica el poder de las tinieblas ( $v$. 53b). Nótese, además, que Jn presenta el suceso en un "huerto", que aparecerá también más tarde en el relato de la sepultura de Jesús $(19,41)$, como si quisiera colocar en paralelismo antitético la historia del primer pecado y la de la redención, si bien lo que se destaca como realizado en el "huerto" es la confrontación de Jesús con sus adversarios, encabezados por Judas, que representa a Satanás ${ }^{59}$, y la victoria de Jesús sobre sus enemigos ${ }^{60}$.

Sobre la determinación precisa de la gente que acompaña a Judas no coinciden los evangelistas. Según Mc-Mt, se trata más bien de una multitud o chusma mercenaria (Mt añade numerosa). Según Mt, fueron enviados de parte de los príncipes de los sacer. dotes y de los ancianos del pueblo, expresión en la que aparece su perspectiva eclesial: ya en el prendimiento existe una oposición tremenda entre Jesús y los dirigentes de Israel. Mc añade, además de parte de los escribas ${ }^{61}$, destacando sin atenuantes que la oposición hacia Jesús es completa: la autoridad religiosa, magistral y política del Judaísmo (=el Sanedrín) conspira contra Jesús.

El Sanedrin, que ejercía funciones de todo tipo entre los judíos excepto la aplicación de la pena de muerte, tenía a su dispo-

58. Cfr. H. Reynen, "Sinagesthai: Joh 18,2", en Bibl Zeit 5 (1961) 86-90.

59. Cfr. Jn 13, 2.27.30.

60. Cfr. R. E. BRown, The Gospel according to John, II (London 1966) 806;

R. SCHNACKENBURG, Das Johannesevangelium, III, 250, nota 6.

61. Son recordados en textos similares: 8,$31 ; 11,27 ; 14,53 ; 15,1$. 
sición dos grupos de servidores principales: los "levitas", que, aparte de otras funciones litúrgicas, ejercían el poder policíaco dentro del templo y en casos excepcionales también fuera, y otros órganos policiales y judiciales, que vigilaban otros lugares e incluso podían hacer detenciones. Este poder de la autoridad judía es un hecho legal, pues Roma solía respetar en su mayor parte los poderes locales, aunque siempre sometidos al imperio ${ }^{62}$. De hecho Lc menciona aquí, como en el pacto entre Judas y el Sanedrín (22, 4), la participación de los policias o jefes de la guardia del templo (que solían tomarse de entre los levitas), a los que puede haber pertenecido el siervo del Sumo Sacerdote, que figura en todos los relatos. Aparecen también en Lc entre la tropa pontífices, designando tal vez a ciertos miembros delegados por el Sanedrín para supervisar toda aquella operación ${ }^{63}$.

La modificación juánica de esta descripción es más sorprendente: Judas tomó consigo la cohorte y los guardias de los pontífices y fariseos. La "cohorte" indica evidentemente la guarnición romana en Jerusalén (en el v. 12 habla del "tribuno", que seguramente la mandaba) y normalmente designa la unidad militar romana de 600 hombres. Como Jn habla al mismo tiempo de "los guardias de los pontífices y fariseos", supone que el grupo que viene a prender a Jesús estaba compuesto por judíos, a los que acompañaba un pequeño destacamento romano. Aunque a veces se acuse al cuarto evangelisia de haber ampliado, por razones teológicas, el aparato de los poderes mundanos que intervienen en el prendimiento de Jesús ${ }^{64}$, la intromisión de tropas romanas en este primer estadio del proceso cuadra perfectamente con el trasfondo histórico de la narración de la pasión. No sólo es probable, sino casi inevitable, que algunos soldados romanos (que solían ser sirios, reclutados en la provincia vecina) participasen en el prendimiento de Jesús. Es difícilmente imaginable que cualquier banda o grupo armado, por pequeño que fuese, hubiera podido pasar inadvertido sin que los romanos lo aprobasen previamente, sobre todo en la época pascual, propicia para las revueltas. Por tanto, puede aceptarse como verídico lo que nos transmite el cuarto evangelio ${ }^{65}$.

62. Cfr. J. Blinzleg, Il processo di Gesù (Brescia 1966) 73-84.

63. Sin embargo, como se dirá más adelante, es fácil que este v. 52 esté fuera de su contexto cronológico.

64. Cfr. J. BLINZLeR, o. c., 80-82; H. VAN DEN BUSSCFE, El Evangelio según San Juan (Madrid 1972) $593 \mathrm{~s}$; P. Benort, o. c., $60 \mathrm{~s}$; E. HaENCheN, "Historie und Geschichte...", 60.

65. Cfr. M. Goguel, Jésus (Paris 1950) 374; A. Wikenhauser, o. c., $474 \mathrm{ss;}$ 
En cuanto al número de esta tropa, no debe suponerse una gran multitud, a pesar de la expresión de Mt "turba numerosa" y de Jn "la cohorte y los guardias de los pontífices". El concepto de muchos o pocos está en función de la misión a la que se destina. El término "cohorte". no parece que sea usado por el evangelista en sentido técnico $(=600$ soldados $)$; podían ser un simple pelotón de tropa con un tribuno al frente. Por lo demás, las circunstancias del episodio imponen una notable reducción. Acaso unos $50 \mathrm{hom}$ bres, entre todas las clases designadas, fueron más que suficientes para aquella operación ${ }^{66}$.

El armamento que llevaban responde a la situación y al ambiente. Mc-Mt los presentan armados de espadas y garrotes. Jn Ios describe portando linternas, antorchas y armas (¿espadas, lanzas?), elementos ordinarios de un equipo militar. A pesar de estar en la luna llena del mes de Nisán, era conveniente tomar las precauciones necesarias. Las sombras y recovecos de los olivos de Gethsemani, así como la constitución cavernosa del terreno, podian ser muy propicios para el escondite o la huída. Algunos críticos, sin embargo, ven en las linternas y antorchas un sentido simbólico: su débil luz acentúa alrededor la obscuridad profunda de la noche de la pasión ${ }^{67}$.

Beso de Judas y respuesta de Jesús (Mc 14, 44-45; Mt 26, 48-50a; Lc 22, 47c-48):

Como posiblemente varios de los que venían con Judas a prender a Jesús no conocian a éste personalmente, por ser soldados mercenarios, o aunque le conociesen tal vez no le distinguian bien de sus discipulos, debido a la hora nocturna en que debia efectuarse el prendimiento ${ }^{68}$, Judas les había dado una contraseña segura e inconfundible de identificación: a quien yo besare, ése es (Mc-Mt). Un gesto familiar e inocente y pacifico en apariencia, expresión normal de cariño y amor, pero que en este caso tiene todas las características de una verdadera traición ${ }^{69}$.

R. E. Brown, o. c., 807; A. DAUER, Die Passionsgeschichte im Johannesevangelium, 27.

66. Cfr. M. DE TUYA, o. c., 320.

67. Cfr. C. K. Barret, o. c., 433 ; R. E. BRoWN, o. c., 809

68 Solamente $\mathrm{Jn}$, que omite el beso de Judas, ha pensado en las linternas $\mathrm{y}$ antorchas

69. G. SCHLAEGER ("Die Ungeschichtlichkeit des Verräters Judas", en Zeit 
Judas mismo les recomienda proceder con decisión y cautela: prendedle y llevadle con cautela $(\mathrm{Mc})$, expresión última que $\mathrm{Mt}$ omite por superflua o descortés e irreverente hacia Jesús. Judas pudo insistir en esto por temor de una revuelta por parte de sus discípulos o por la experiencia de otras ocasiones en las que Jesús había desaparecido hábil o prodigiosamente ${ }^{70}$.

Con estas precauciones Judas se acerca a Jesús ${ }^{71}$ y le dice: jsalve Rabbi! Y le besó. En Mc "rabbi" es un título normal aplicado a Jesús ${ }^{72}$. En Mt, sin embargo, tiene un matiz despreciativo (cfr. $23,7-8)$. Sólo es puesto en boca de Judas para designar a Jesús ${ }^{73}$. Se percibe en ello la situación psicológica de la iglesia de $\mathrm{Mt}$-el apelativo "rabbi" pertenece a la sinagoga - en medio de un ambiente judaico ". El verbo compuesto "kataphileo", aquí usado, denota un besar con intensidad o reiteradamente, lo que se adapta mejor al contexto, tanto para disimular más hipócritamente sus intenciones ante Jesús y los discípulos como para que la tropa, en la penumbra de aquel olivar, se percatase mejor de quién era Jesús.

Lc presenta a Judas acercándose a Jesús para besarle, pero calla el hecho. Repugna a su devoción hacia Jesús la narración directa de la ofensa. Cierra, por así decirlo, los ojos en el momento oportuno, no apareciendo si realmente lo besa o no. Lo mismo acontecerá en otras ocasiones similares.

Antes esta traición villana e inicua de Judas, Mt pone en boca de Jesús una frase cuyo sentido preciso es muy discutido por la expresión estereotipada, proverbial y un tanto elíptica del original griego ${ }^{75}$. Puede traducirse: camarada o socio (mejor que "amigo"), ja lo que estás aquí! (o "haz a lo que viniste"). Contiene un cierto

Neut Wiss 15, 1914, 50-59), siguiendo los pasos de R. Bultmann y G. Bertram, ha sostenido que el episodio no es un hecho histórico, sino una leyenda o mito, que representa en la persona de Judas al pueblo judio. Argumentación contraria puede verse en $\mathrm{D}$. HAUGG, Judas Iskarioth in den neuentestamentichen Berichten (Freiburg 1930) $158 \mathrm{~s}$.

70. Cfr. Lc 4, 28-30; Jn 8,$59 ; 10,39$.

71. La frase en Mc es menos elegante y reverente, pero más expresiva: $y$ llegando, enseguida acercándose a él...

72. Cfr. 9,$5 ; 10,51$.

73. Cfr. 26,25 .

74. Cfr. A. VANhoye, De narrationibus passionis, 51-52

75. Cfr. F. REhkopf, "Mt 26,50, Etaire ef'o parei", en Zeit Neut Wiss 52 (1961) 109-115; W. ElTESTER, "Freund, wozu du gekommen bist (Mt 26,50)", en Neotest et Patrist. Hommage O. Cullmann (Leiden 1962) 70-91; G. M. LEE, "Matthew XXVI: 50", en Exp Times 81 (1969-70) 55. 
matiz de reproche y vituperio ${ }^{76}$, invitándole a abreviar los cumplimientos hipócritas ${ }^{77}$. En todo caso las palabras de Jesús manifiestan su presciencia (ya lo sabe de antemano y no le puede engañar) y plena autonomia, pues como Señor, dirige los acontecimientos conforme al plan salvífico divino, de modo que su prendimiento no deberá ser motivo de escándalo para la fe ${ }^{78}$.

Lc es quien presenta más claramente el significado teológico de dicha acción y la gran distancia, o mejor, la oposición completa que se da entre el discípulo y el Maestro: Judas, ¿con un beso entregas al Hijo del Hombre? La fuerza de la frase y su valor parenético resalta más, porque es Jesús mismo quien se dirige al traidor y en el momento de la traición. La dimensión teológica está contenida en el título "Hijo del Hombre", cuyo trágico destino ${ }^{79}$ comienza a realizarse por ese gesto traidor de un discípulo.

Una vez más los sinópticos no nos transmiten materialmente, como registración magnetofónica, las mismas palabras de Jesús, sino que cada uno, según su psicología y teología, nos ofrece el significado de la escena. Mt presenta aqui una respuesta digna de Jesús; Lc resume la situación de manera majestuosa. Si fuera necesario escoger la auténtica sentencia de Jesús en esta ocasión, sería preferible decidirse por la contenida en $\mathrm{Mt}$, lo que no quiere decir que la de Lc sea falsa.

\section{Retroceso de Jesús y caida en tierra del grupo de Ju- das ante la presencia de Jesús (Jn 18, 4-9):}

Jn sustituye la escena del beso de Judas por ésta, cuya motivación $e$ interés parecen ser decididamente teológicos. El evangelista subraya de nuevo (cfr. 13,1) ahora, al comenzar los relatos de la pasión, la plena conciencia de Jesús sobre su destino. Jesús, perfectamente consciente de cuanto le iba a suceder... Destaca, además, su iniciativa al entregarse libremente y su solicitud para

76. Cfr. Sal 55, 13-14. 21-22.

77. Varios autores, v. gr., M. DibenIUs ("Judas und der Judakuss", en Botschaft und Geschichte, I, Tübigen 1953, 272-277), R. BultmanN (Die Geschichte der synoptische Tradition, Göttingen 1957, 340-341), A. H. Mc'NeILE (The Gospel according to Saint Matthew, London 1915, 394) juzgan la escena como "tendencia novelistica" de Mt.

78. Cfr. G. STRECKER, Der Weg der Gerechtigkeit, 182.

79. Cfr. 18,$31 ; 22,22 ; 24,7$. 
con los discípulos, atestiguando como los sinópticos, pero de modo distinto, cómo Jesús cumple las Escrituras, rehúsa defenderse y acepta y conduce su destino ${ }^{80}$.

Si se concibe como histórica esta escena, debe situarse prácticamente a la llegada de Judas con su grupo al huerto. Jesús toma la iniciativa, se adelanta $y$, saliéndoles al encuentro, les pregunta: ¿a quién buscáis? La respuesta a Jesús Nazareno, que en boca de los adversarios es una fórmula de reconocimiento (=nombre por el que se conocía generalmente a Jesús), para el evangelista indica el origen humano y humilde de Jesús y en cierto modo el escándalo de la Encarnación ${ }^{81}$, en fuerte oposición con la declaración de su transcendencia en la respuesta de Jesús: Yo soy. Esta expresión cortada que algunos críticos conciben como fórmula de reconocimiento (=yo soy Jesús), es frecuentemente puesta en boca de Jesús por el evangelista, tanto en sentido absoluto ${ }^{82}$, como con complemento ${ }^{83}$. Con ella se revela Jesús a los ojos de la fe en su misterio y majestad divinos ${ }^{84}$, evocando la manifestación de Dios a Israel, como verdadero Dios ${ }^{85}$, y la descripción e identificación de Dios a Moisés en el Sinaí ${ }^{86}$.

En el momento en que Jesús declara su identificación Judas, el que le entregaba —repite Jn- estaba también con ellos. La confrontación de estos dos personajes es la confrontación de dos potestades, cuyo combate va a adquirir un tono escatológico (cfr. 12, 31-32).

Ante la inesperada y espontánea respuesta de Jesús, los agentes del poder de Satanás retrocedieron y cayeron en tierra. La expresión se inspira en modelos veterotestamentarios ${ }^{87}$ : la cohorte se echa hacia atrás, lo mismo que los enemigos de Israel y del justo,

80. Cfr. G. RIchter, "Die Gefangennahme Jesu...", 26-39; A. Dader, o. c., $30 \mathrm{~s}, 37 \mathrm{~s}$.

81. Cfr. D. Mollat, "Remarques sur le vocabulaire spatial du quatrième Evangile", en Stud Evang 1 (1959) 332.

82. Cfr. 4,$26 ; 6,20 ; 8,24.28 .58 ; 13,19$.

83. Cfr. 6,$35 ; 8,12 ; 10,7.11 ; 11,25 ; 14,6 ; 15,1$.

84. Sobre el tema cfr. H. Zimmermann, "Das absolute 'Ego eimi' als die neutestamentliche Offenbarungsformel", en Bibl Zeit 4 (1960) 54-69, 266-276; A. FEUILLET, "Les Ego eimi christologiques du quatrième Evangile", en Rev Scien Relig 54 (1966) 5-22, 213-240; P. B. HARNER, The "I am" of the Fourth Gospel, Philadelphia 1971; K. P. JOERNS, "Die johanneischen 'ich bin' Worte", en Deutsches Pfarramtblat 71 (1971) 741-744; R. E. BRown, o. c., I, 533-538; R. ScHNACKENBURG, o. c., II, 59-70.

85. Cfr. Is $43,10.25 ; 46,4-9 ; 47,8 ; 51,12$.

86. Cfr. Ex 3,14.

87. Cfr. Sal 35,$4 ; 56,9 ; 27,2-3$. 
cuando Yahvé vuela en su ayuda. Menos acomodada a las circunstancias es la explicación que entiende "cayeron en tierra" como manifestación de temor y reverencia, como en las teofanías bíblicas ${ }^{88}$, ya que aquí se trata más bien de destacar la impotencia de los enemigos de Jesús ante la plenitud de poder y libre autonomía de Jesús ${ }^{89}$. Descabellada parece a todas luces la explicación naturalista: bastaria que, impresionados por la majestad de Jesús, que avanza decidido y voluntarioso hacia ellos, retrocedan un po$c o$, tropiecen con las raíces de los olivos y tal vez algunos caigan al suelo.

La repetición de la pregunta y respuesta y el mismo contexto de todo este pasaje subrayan la superioridad sobrenatural de Jesús, así como su pleno consentimiento en el caminar hacia la muerte. Lo mismo que había dado a Judas la señal para que se fuera por la noche (cfr. 13,27), da ahora él mismo la señal de su arresto, pero ordenándoles que dejen libres a sus discípulos: si me buscáis a mi, dejad marchar a éstos.

La huida de los discipulos, que recogen los sinópticos y Jn presupone, fue un recuerdo penoso entre los primeros cristianos. Se ha atribuido a Jn el intento de justificarla, como en los apócrifos. Sin embargo, Jn no denuncia ni excusa psicológicamente su cobardía, sino que la considera en una perspectiva teológica ${ }^{90}$. Jesús manifiesta así la solicitud del pastor para con sus ovejas (cfr. 10, 11-15) y, ordenando la liberación de sus discípulos, muestra que sólo El debe morir (cfr. 11,50).

En esta amorosa solicitud por los discípulos descubre también el evangelista el cumplimiento de una palabra anterior de Jesús: no he perdido a ninguno de los que me has dado. La fórmula para que se cumpliera lo que habia dicho, típicamente juánica ${ }^{91}$, se aplica a la Escriura y a las palabras de Jesús, que gozan de autoridad divina. Generalmente se acepta que se refiere a Jn 17,12 ó 6,39, aunque tales palabras se refieren claramente a la preservación de la perdición escatológica, mientras aquí se aplica a la superación de un peligro corporal. Es cierto, sin embargo, que para los discípulos, que antes de la resurrección de Jesús no estaban preparados para afrontar la muerte, el peligro del morir físico era también un

88. Cfr. Dan 2,$46 ; 8,18 ;$ Ap 1,17 .

89. Cfr. In $7,30.44 ; 8,20 ; 10,39$, etc. Cfr. R. Schnackenburg, o. c., III, $253 \mathrm{~s}$.

90. Cfr. C. H. DoDd, Historical Tradition in the Fourth Gospel (Cambridge 1976) 76 ; A. DAUER, o. c. 39-40.

91. Cfr. 12,$38 ; 13,18 ; 15,25 ; 17,12 ; 18,32 ; 19,24.36$. 
peligro de perdición espiritual. Más aún: la salvaguarda del cuerpo y del espíritu de los discipulos son etapas en el camino de la historia de la salvación y expresiones sucesivas de la firme voluntad redentora del Padre por Jesús. Era preciso que los discípulos vivieran la revelación de la muerte-exaltación del Maestro a la luz del Espíritu y dieran testimonio de ella. La salvación de su fe durante la vida pública de Jesús, como la de sus vidas en el momento de su muerte, adquieren su pleno significado cuando se las encuadra en el plan salvífico de Dios ${ }^{22}$.

Intervención defensora de Pedro y respuesta de Jesús (MC 14,47; Mt 26, 51-54; Lc 22, 49-51; Jn 18, 10-11):

Después de la escena anterior (Jn), o después del beso de Judas ( $\mathrm{LC}$ ), o después de ser prendido (Mc-Mt), tiene lugar el ataque impulsivo y feroz de Pedro al siervo del Pontífice y la reprensión de Jesús al discípulo. La descripción es un tanto diversa en cada evangelio.

Mc y Mt se limitan a indicar de modo indeterminado la acción defensiva y sus efectos: uno de los presentes (Mc) o uno de los que estaban con Jesús (Mt) echó mano a su espada, la sacó e, hiriendo al siervo del Sumo Sacerdote, le cortó la oreja (Mc dice la orejita). La expresión vaga y la intervención rápida sugiere que Mc, que presta mayor atención a los hechos que a las personas, conoce la persona de que se trata y dirige la atención del lector hacia el vehemente Pedro.

Lc presenta una narración más ordenada y sitúa este conato de resistencia antes del prendimiento. Destacando, como $\mathrm{Mt}_{\text {, la re- }}$ lación de los discípulos con Jesús, escribe: viendo los que estaban con El lo que iba a suceder, ya que los enemigos se disponian con impetu y en tropel a prender a Jesús, dijeron: Señor, ¿acometemos o herimos con la espada? Los discípulos aparecen conscientes de su relación y deber hacia el Maestro y respetuosamente le interrogan qué debe hacerse, pues $\mathrm{El}$ es el Señor. Pero constata también, aunque no nombra (=uno de ellos), la iniciativa espontánea de Pedro, quien, sin esperar respuesta, acometió de improviso con una de las espadas que portaban los discípulos (cfr. 22,38) e hirió al siervo del Sumo Sacerdote y le cortó la oreja derecha. Este últi-

92. Cfr. H. VAN DEN Bussche, o. c., $597 \mathrm{~s}$. 
mo dato (=la oreja derecha) y la identidad del discípulo defensor (=Simón Pedro) y del siervo del Pontífice (=Malcos) son aportados también por $\mathrm{Jn}$, en el que predominan las descripciones concretas y detalladas.

La identificación de Malcos, que según R. Bultmann ${ }^{93}$ se debe a la tendencia popular a identificar las personas anónimas, parece ser un dato antiguo, histórico, ya que $\mathrm{Jn}$ (o el autor de la fuente o datos usados por $\mathrm{Jn}$ ) conocía bien la casa y servidumbre del Sumo Sacerdote (cfr. 18, 15-16) y, por otra parte, es un nombre desconocido, lo que favorece aún más su historicidad. Probablemente era el jefe que mandaba el grupo enviado por los sumos sacerdotes y fariseos y quien se abalanzó primero sobre Jesús ${ }^{94}$. La anotación "la oreja derecha" puede acentuar el gran deshonor infligido por Pedro a Malcos, pues es más natural, frente a un enemigo, herirle o cortarle la izquierda ${ }^{95}$.

Ante este acto de legitima defensa, Jesús, viéndolo al margen que estaba de la prudencia, pues eran pocos contra toda una tropa, y sobre todo, al margen que estaba de los planes del Padre, dirigiéndose a Pedro (a los discípulos en Lc) detiene el intento de defensa y le da orden terminante de no usar la espada. Todos los evangelistas, excepto Mc, atribuyen a Jesús algún dicho muy apropiado en esta ocasión.

En Lc la respuesta aparece un poco obscura. De ahí las diversas traducciones. La expresión pero Jesús dijo puede tener sentido diverso e indicar también que Jesús responde ahora a la interrogación anterior de los discípulos (v. 49). Con la tranquila respuesta dejad hacer hasta esto (o ¡dejad! ¡basta ya!), Jesús disuade la acción violenta sin dar razones (cfr. 22,38). Los discípulos pueden pensar que las cosas no irán más lejos de donde quiera Jesús para poner límite a sus adversarios. Incluso se muestra magnánimo para con sus enemigos $y$, tocando la oreja, le curó. Con este dato, exclusivo de Lc, el evangelista presenta a Jesús solícito hacia la persona herida y practicando el amor a los enemigos, que antes enseñó $(6,27-35)$. No hay por qué suponer que Lc ha inventado este detalle. Dada su calidad de médico y su espíritu compa-

93. Das Evangelium nach Johannes (Göttingen 1964) 496 nota 1.

94. N. KRIEGER ("Der Knecht des Hohenspriesters", en Nov Test 2, 1957-58, 73-74) identifica (!) al siervo del Sumo Sacerdote con la persona de Judas, a quien los discípulos habrían designado así por su traición y servicio al sumo Sacerdote.

95. Cfr. P. Benoit, o. c., 58; M. RostovtzeFF, "Hous dexion apotémnein" en Zeit Neut Wiss 33 (1934) 196-199. 
sivo, ha podido conservar un detalle tradicional que los otros evangelistas han omitido ${ }^{\circ}$.

In -aqui en estrecho paralelismo con Mt- atento siempre al sentido teológico de los acontecimientos ${ }^{97}$, con una frase que alude a la tradición de la oración de Jesús en Gethsemani, prohíbe a Pedro poner resistencia (=vuelve tu espada a la vaina), aduciendo como motivo el hecho de que la pasión y la muerte le han sido impuestos por el Padre (=el cáliz que me ha dado el Padre ino lo voy a beber?), a cuya voluntad debe plegarse obediente (cfr. 14, 31). Esta aceptación del cáliz equivale al motivo del cumplimiento de las Escrituras en los sinópticos.

Mt, con su peculiar orientación doctrinal, reprueba el intento defensivo de Pedro con un precepto perfectamente determinado (=vuelve tu espada a su sitio), que razona triplemente. La primera explicación es un principio general, de sabor proverbial y con marcada alusión a la ley del talión y del go' el, en el que se recrimina toda violencia: porque todos los que empuñan la espada, a espada perecerán ${ }^{98}$. La expresión, en forma quiásmica, nada afirma sobre los derechos morales de los que le vienen a prender, ni niega el derecho de defenderse, ni el poder judicial de la autoridad para dar muerte. Recusa la violencia, pues engendra violencia y es contraria al espíritu evangélico y cristiano ${ }^{99}$.

El segundo argumento se funda en la especial relación de Jesús con el Padre: ¿o piensas que no puedo yo rogar a mi Padre, que pondria al instante a mi disposición más de doce legiones de ángeles? Corrige la idea de que Jesús no tenga otra posibilidad de defensa que no sea la humana y destaca, como verdad familiar a los discipulos, la doctrina fundamental mateana de la relación de Jesús con Dios Padre ${ }^{100}$. En esta relación filial se funda la certeza de ser escuchado y socorrido instantáneamente. La expresión "más de doce legiones de ángeles" puede ser metafórica e hiperbólica para designar que Jesús dispone de otros medios para defenderse,

96. J. W. DoEve (Die Gefangennahme...", 470, con excesiva imaginación opina que el dato deriva de Am 3,12.

97. Cfr. C. K. BaRRET, o. c., 436.

98. H. Kosmala, ("Matthew XXVI: 52 - A Quotation from the Targum", en Nov Test 4, 1960, 3-4) relaciona esta sentencia con Ap 13,10 y con una paráfrasis del Targum de Is 50,11. De ella se serviria Mt para ilustrar su perspectiva doctrinal.

99. Cfr. Mt 5,39; 1 Tes 5,15; Rom 12, 17-21; 1 Pe 3,9.

100. Cfr. $7.21 ; 10,32.33 ; 11,27$, etc. 
si conviniese neutralizar su prisión por aquella tropa y en aquella hora. La descripción de los ángeles como un ejército y su intervención bélica es plenamente bíblica ${ }^{10}$, era una concepción común en los tiempos neotestamentarios y evoca las legiones romanas y la doctrina qumránica sobre la gran batalla entre Dios y Satán con sus ejércitos celeste y terrestre ${ }^{102}$.

El recurso a este medio de defensa es rehusado también a la luz del tercer argumento: la relación de su prendimiento con las Escrituras (=mas ¿cómo se cumplirán las Escrituras de que asi debe suceder?). Así pues, el plan divino sobre Jesús debe realizarse no por medio de armas humanas, ni por la intervención angélica, sino por la aceptación sin resistencia de su arresto y prendimiento.

\title{
Palabras de Jesús a sus adversarios
}

\author{
(Mc 14, 48-49; Mt 26, 55-56a; Lc 22, 52-53):
}

Los tres sinópticos, aunque con distinta redacción y secuencia cronológica, añaden al episodio del prendimiento unas palabras que dirigió Jesús a la tropa que venía a prenderle. El cuarto evangelio las omite, pero en el episodio de Jesús ante Anás $(18,20)$ resuenan algunos temas y vocablos de esta escena sinóptica. En este breve discurso, muy similar en parte en los sinópticos, Jesús reprocha a sus adversarios el modo vil e injurioso como van a prenderle y afirma la llegada de la hora de su voluntaria entrega en cumplimiento de la voluntad del Padre.

Primero con gran ironia les echa en cara la vileza e indignidad con que vienen a prenderle: ¿como contra un salteador habéis salido a prenderme con espadas y palos? Si el hecho es injusto, el modo es indigno. El vocablo "salteador" debe entenderse normalmente como "ladrón o bandido" de caminos ${ }^{103}$, aunque en los tiempos neotestamentarios se aplicaba también a los revolucionarios, sediciosos o terroristas ${ }^{104}$.

En segundo lugar afirma su entrega voluntaria en cumplimien-

101. Cfr. Jos 5,14; 1 Re 22,19; Sal 142,2; 2 Mac 10, 29-30; Dan 12,1.

102. Cfr. STRACK-BILleRBECK, Kommentar aum Neuen Testament aus Talmud und. Midrash, I (München 1922) 997; W. Grundmann, Das Evang. nach Matthäus, 543. El número "doce" puede hacer referencia a los discípulos. Cfr. I. GomÁ, El Evangelio según San Mateo, II (Madrid 1976) 630.

103. Cfr. Lc 10,30.36; Mc 15,27; Mt 27,39.

104. Cfr. Jn 18,40; Lc 23,19. 
to de la voluntad del Padre: cada (o mejor, durante el) dia estaba con vosotros enseñando en el templo y no me detuvisteis (o no pusisteis sobre mi las manos, como dice Lc). Precisamente en varias ocasiones quisieron prenderle y, teniéndole completamente a mano, no pudieron ${ }^{105}$. En cambio ahora ha llegado vuestra hora $y$ el poder de las tinieblas (LC), esto es, la hora en que se cumplan las Escrituras (Mc), que Mt amplia al cumplimiento general de las Escrituras de los protetas ${ }^{106}$.

En Mc en general se destaca lo paradójico del suceso. Cuando han podido arrestar fácilmente a Jesús (cfr. 11,18; 12,12), no lo han hecho y han elegido este modo absurdo, injurioso y ridículo, persiguiendo fuera de la ciudad, como a un ladrón peligroso, al que aceptaban como maestro en el templo. También resulta paradójico que, mientras "uno de los asistentes" actúa, Jesús, el que debia actuar, pues gozaba de gran poder taumatúrgico, nada hace; se contenta con hablar y entregarse pasivamente ${ }^{107}$. La clave de esta paradoja es presentada breve, obscura y enigmáticamente: para que se cumplan las Escrituras. Tal vez se refiere a ls 53,12 (= "fue contado con los rebeldes"), citada por Lc 22, 37.

Mt ofrece una conexión cronológica más estricta, aunque vaga, de esta declaración de Jesús con la escena anterior (=en aquel momento), presenta de modo más digno y solemne a Jesús ( $=$ me sentaba... para enseñar: cfr. 5,1$)$ e insiste de nuevo, ahora explícita y didácíicamente, en que la pasión de Jesús acontece como cumplimiento del plan divino, con lo que el posible carácter escandaloso de la pasión y cruz de Jesús pierde su fuerza ${ }^{108}$.

Lc introduce de modo particular esta declaración pública de Jesús, enumerando las personas a las que se dirige y de las que se afirma que están presentes: dijo Jesús a los sumos sacerdotes, jefes de la guardia del templo y ancianos que habian venido contra él. Se dirige, pues, a las autoridades judias enumeradas y no a la tropa enviada por ellas. Omite, además, la expresión marciana "para prenderme", pues no le agrada insistir en el prendimiento, y habla de la "hora" y las "tinieblas" (=esta es vuestra hora y el poder de las tinieblas), temas especificamente juánicos. Sin embar-

105. Cfr. Lc 19, 47-48; 20,19 y par.; Jn 7,30. 44-53.

106. Sobre el cumplimiento de la Escritura en la pasión de Jesús, cfr. $\mathbf{K}$. H. SchelKie, Die Passion Jesu, 81-109; D. P. SENIOR, The Passion Narrative according to Matthew, 142-155.

107. Cfr. A. Vanhoye, o. c., 48.

108. Cfr. H. W Bartsch, "Die Bedeutung des Sterbens Jesu", en Theol Zeit 20 (1964) 87-102, espec. 92-93. 
go, esta analogía con la terminología juánica es sólo superficial, aparente. En Jn la "hora" es siempre la "hora de Jesús" y designa su pasión-glorificación ${ }^{109}$, mientras en Lc es la "hora de los adversarios" de Jesús, relacionándola por oposición a "aquella hora" $(20,19)$ en que nada pudieron contra Jesús. Tampoco In afirma que la pasión sea "el poder de las tinieblas", mientras en Lc "el poder de las tinieblas" ataca y tienta a Jesús, de manera que la pasión es el ataque y la tentación furibunda de Satán contra Jesús ${ }^{110}$, momento para el que Jesús se ha preparado orando al Padre y recomendando a sus discípulos hacer lo mismo $(22,40.46)$.

Conviene notar que en la evocación del ministerio didáctico de Jesús en el templo, éste se presenta largo, duradero, lo que conviene mejor con la descripción y cronología juánica que con la sinóptica. Sin embargo, Lc ha preparado ya esta declaración de Jesús ${ }^{111}$. Se observa, además, que en los sinópticos la conexión de estas palabras de Jesús con lo anterior es muy tenue. Mc antepone una introducción solemne: $y$, respondiendo Jesús, les dijo. Mt presenta una expresión más formal, pero vaga: en aquella hora dijo Jesús a la turba. Lc presenta unos oyentes que, según Mc-Mt, no están en Gethsemaní, sino más bien en casa del Sumo Sacerdote. Surge, pues, justamente la duda de su verdadera colocación en este contexto cronológico, duda que aumenta al comparar su contenido con la declaración de Jesús ante Anás (Jn 18,20). El contexto de la interrogación y de la respuesta conviene mejor a la tradición juánica, en la que los agentes son los mismos que en Lc. Es presumible, pues, que la declaración sinóptica refiera palabras de Jesús que éste dijo no en el prendimiento sino en la interrogación nocturna ante Anás. La tradición, que recordaba estas palabras, olvidó paulatinamente su contexto. Mc las relacionó con el prendimiento y las utilizó para concluir esta escena. Mt y, sobre todo, Lc eran conscientes de su origen y situación diversa y por eso cambiaron un tanto su conexión con el contexto ${ }^{112}$.

\section{Prendimiento de Jesús}

(Mc 14,46; Mt 26,50b; Lc 22,54a; In 18,12a):

Los cuatro evangelistas testimonian el hecho, aunque con di-

109. Cfr. A. GEORGE, "L'Hore' de Jean XVII", en Rev Bibl 61 (1954) 392397; W. Thuesing, Erhöhung..., 75-100; M. BaLAGdE, "La hora de Jesús", en Rev Bibl Calas 31 (1969) 82-85; R. SchNACKENBURG, o. c., II, 484.

110. Cfr. 4,$13 ; 22,3$.

111. Cfr. 19,$47 ; 21,37$.

112. Cfr. P. Benort, o. c., 100 ; A. VANhoYe, o. c., $64 \mathrm{~s}$. 
versa secuencia temporal. En Mc y Mt tiene lugar después del gesto traidor de Judas y antes del intento de defensa de Pedro. Su descripción es breve, dura en Mc y más ceremoniosa en Mt: entonces adelantándose, le echaron mano (a Jesús, en $\mathrm{Mt}$ ) y le prendieron. En Lc y Jn aparece como conclusión de todo el episodio y como introducción al proceso ante las autoridades judias: entonces la cohorte, el tribuno y los guardias de los judios prendieron a Jesús... (Jn), si bien Lc se resiste a afirmar explícitamente el hecho del prendimiento, recordándolo solamente de paso: entonces, prendiéndole, se lo llevaron...

\section{Los discípulos abandonan a Jesús y huyen}

(Mc 14,50; Mt 26,56b):

La huida de los discípulos, atestiguada por Mc y $\mathrm{Mt}$; con toda probabilidad sucedió simultáneamente al prendimiento de Jesús. Mc observa el hecho de forma cruda e indeterminada: y abandonándole, huyeron. Mt corrige la expresión marciana, excluyendo toda posibilidad de confusión: entonces los discipulos le abandonaron todos y huyeron. Con ello se pone de relieve el cumplimiento de la palabra de Jesús en el Cenáculo sobre su dispersión y abandono ${ }^{113}$, recordando el oráculo deuterozacariano: "heriré al pastor y se dispersarán las ovejas" (Zac 13,7). No obstante, según Jn 18, 15 , Pedro y otro discípulo, repuestos de la primera impresión, seguirán a Jesús, aunque de lejos, hasta entrar en casa de! Sumo Sacerdote.

In omite esta escena, aunque la conoce ${ }^{114}$, y la interpreta en su aspecto positivo, como efecto de la solicitud de Jesús para con sus discípulos ${ }^{115}$. Lc la omite también, pero por diverso moivo. Aunque en 22, 31-32 la supone y habla de la solicitud de Jesús, especialmente con Pedro, aqui la suprime por consideración hacia los discípulos. Lc generalmente tiene siempre gran respeto a las personas $^{116}$.

\section{El joven cubierto con un lienzo y su huida}

\section{(Mc 14, 51-52):}

Mc es el único que añade esta escena, extraña y pintoresca,

113. Cfr. Mc 14,27 y par.

114. Cfr. 16,$32 ; 18,9$.

115. Cfr. G. Richter, $l$. c., 31. Véase lo indicado en la pág. 29.

116. Cfr. K. H. SchelkLe, Die Passion Jesu, 17-24. 
en este momento: un joven le seguia cubierto sólo con un lienzo; y le detienen. Pero él, dejando el lienzo, se escapó desnudo.

Aunque no parece estar de acuerdo con la dignidad del momento y del "evangelio", Mc no se avergüenza ni duda en mantener este detalle inesperado, sobre cuyo valor y contenido se han desbordado las conjeturas. Su minuciosidad $e$ insignificancia en un momento de tal gravedad es para unos la mayor prueba de su historicidad; si lo narró es porque ocurrió así y tal vez dicho joven sea Marcos mismo o haga relación a un testigo presencial del suceso ${ }^{117}$. Otros, por el contrario, prefieren ver en ello un significado simbólico, que Mc no explica ${ }^{118}$, una alusión a Am 2,16 ${ }^{119}$, el signo de la angustia escatológica (cfr. Mc 13,14.16) ${ }^{120} \circ$ más probablemente el presagio enigmático de la suerte de Jesús, ya que la descripción de esta escena tiene muchas semejanzas lexicográficas con los relatos de la sepultura y resurrección de Jesús. Jesús preso, como el joven deienido, huirá de las manos de sus enemigos, abandonando el lienzo y revestido de la estola cándida de la gloria, como el joven del sepulcro ${ }^{121}$.

\section{Conclusión}

El episodio del prendimiento está fundado en los cuatro evangelios, que contienen muchos trazos comunes y otros particulares. La historicidad del suceso es segura. La llegada de Judas y los adversarios de Jesús, el altercado y las tentativas de resistencia de los discípulos, el golpe de espada, la prohibición del intento de defensa, narrados de forma diferente para suministrarnos diversos aspectos del misterio, demuestran la antigüedad de esta tradición

117. Cfr. V. Taylor, The Gospel acc. to Mark, 561s; Ph. Carrington, According to Mark (Cambridge 1960) 321; W. GruNDManN, Das Evangelium nach Markus (Berlin 1959) 297; J. H. McINDos ("The Young Man at the Tomb", en Ev Theol 80, 1968-69, 125) afirma que el joven de Mc 14, 51-52 y 15,5 es el evangelista Marcos, que conocía (Mc 14,28) los preanuncios de Jesús. Increíble (!).

118. Para G. Bertram (Die Leidensgeschichte Jesu und der Christuskult, Göttingen 1922, 51 nota 4) se trata de una "explicación folklórica o popular "de la huida de los discipulos (cfr. Gen 39,12): en el peligro abandonan antes sus vestidos que su vida.

119. Así E. Klostermann (Das Markusevangelium, Tübingen 1936, 153), D. E. Nineham (The Gospel of St. Mark, Cambridge 1965, 397), E. HaencheN (Der Weg Jesu, Berlin 1966, 503, nota 12).

120. Asi A. FARRER, A Study in St. Mark (London 1951) 141; E. HadtotTe, Symbolique du vêtement selon la Bible (Paris 1966) 85.

121. Así A. Vanhoye, "La fuite du jeune homme nu (Mc 14, 51-52)", en Bibl 52 (1971) 401-406; J. RADERMAKERs, La bonne nouvelle de Jésus selon saint Marc (Bruxelles 1974) $373 \mathrm{~s}$. 
evangélica e incluso su función de introducción a la pasión. La lección principal que fluye de todo ello es el deseo de Jesús de cumplir la voluntad del Padre.

Con la evolución de la tradición, la adhesión de Jesús a la voluntad del Padre, su presciencia, su entrega voluntaria, se hacen más explícitas y patentes. El recurso a las Escrituras o el recuerdo de ciertas palabras de Jesús de carácter enigmático o dichas en otro contexto cronológico y redactadas a la luz del acontecimiento de la resurrección, iluminan toda la narración y determinan mejor el valor teológico y religioso de la persona de Jesús y del episodio concreto dentro del plan divino de salvación para instrucción de los fieles. De ahí que la narracción no sea materialmente objetiva en su totalidad y que la redacción no pueda rechazarse sin más como invención arbitraria. 


\section{Ill}

\section{Acontecimientos diversos en la noche des- de el prendimiento de Jesús hasta el amanecer}

(Mc 14, 53-15, 1a; Mt 26, 57-27, 1; Lc 22, 54-23, 1; Jn 18, 23-28)

\section{Problemática sobre los datos transmitidos y su secuencia temporal}

Todas las narraciones evangélicas coinciden en afirmar que, después del prendimiento, Jesús es conducido al Sumo Sacerdote, en cuyo palacio es interrogado, afrentado, negado, juzgado y condenado. En Jn estos dos últimos sucesos no se afirman, aunque se suponen. Sin embargo, en la secuencia temporal de los hechos difieren notablemente, de modo que es imposible obtener de su comparación un cuadro perfectamente coherente. Es evidente que estas narraciones no son completas ni detalladas al maximum, sino que sólo nos transmiten, cada una a su modo, los elementos más importantes, expuestos a la consideración de la fe cristiana ${ }^{122}$.

En Mc y Mt Jesús es conducido inmediatamente ante el Sumo Sacerdote (Mt especifica: "Caifás"), en cuyo palacio y en sesión nocturna comparece ante el Sanedrín, que le juzga y condena como blasfemo. Además, colocan una nueva sesión del Sanedrín, muy de madrugada, indicada breve y enigmáticamente, tal vez para no repetir lo acaecido en la anterior reunión nocturna. Por otra parte, paralelamente a la conducción de Jesús ante el Sumo Sacerdote, introducen a Pedro siguiendo a Jesús a lo lejos. En contraste con

122. P. WINTER ("The Marcan Account of Jesus Trial by Sanhedrin", en Jour Theol Stud 14, 1963, 95-96) señala con fruición las divergencias entre los relatos evangélicos. Cfr. además, P. BoNNARd, Evangelio según San Mateo, 577579 ; R. SchnaCkenburg, o. c., III, $259 \mathrm{~s}$; R. E. Brown, o. c., II, 828 sS. 
la revelación mesiánica de Jesús ante el Sanedrín, narran los ultrajes que recibe a continuación y simuliáneamente las negaciones de Pedro ${ }^{123}$.

Esta forma de presentación ofrece una doble oposición paradójica. La investigación que se hace contra el honor y la autoridad de Jesús sólo obtiene la afirmación de su mesianidad y de su gloria ${ }^{124}$. Contra los testigos, que nada válido aportan, la respuesta de Jesús - culmen del proceso jurídico judío- revela su dignidad y preanuncia su próxima manifestación gloriosa. Por contraste, la revelación de Jesús produce efectos negativos: acusación de blasfemo, condenación oficial, afrentas de parie de los adversarios, negaciones de Pedro, a quien el canto del gallo provoca al llanto. Se trata, pues, de unos sucesos lamentables, paradójicos, de los que en Mc no se da explicación alguna, mientras Mt, dado su carácter más doctrinal, ofrece en el episodio sobre "el precio de la sangre" (27, 3-10) la conclusión y razón que ilumina estos sucesos: el reo es proclamado inocente, mientras los jueces aparecen como reos de "sangre inocente", cumpliéndose en ello el plan divino, conforme a las Escrituras ${ }^{125}$.

Lc, por el contrario, siguiendo un orden más personal y ordenado y evitando ciertas repeticiones marcianas, refiere el traslado de Jesús a casa del Sumo Sacerdote, las negaciones de Pedro y su conversión, los ultrajes contra Jesús y el proceso jurídico judío al amanecer del día siguiente, omitiendo la sesión nocturna de los miembros del Sanedrín, contada por Mc-Mt. Con ello evita ciertos problemas e inverosimilitudes jurídicas, orienta al cristiano a seguir a Cristo paciente, imitando así al discípulo ya convertido, que no entra - como en Mc-Mt- en la serie de los que ultrajan a Jesús, y subraya, como final de estos episodios, el testimonio de Jesús sobre sí mismo, que ilumina su persona y fundamenta la adhesión del discípulo ${ }^{126}$.

Parece que Lc es consciente del problema sobre el valor jurídico de la sesión nocturna del Sanedrín, pues parece contraria a las reglas jurídicas, ya que éste no se reunía más que de día, quedando cerrada durante la noche tanto la sala del tribunal, aneja al templo,

123. Cfr. W. TRILLING, "Die Passion Jesu in der Darstellung der synoptischen Evangelien", en Lebendiges Zeugnis, 1966, Heft 1, 28-46, espec. 31-32; J. L. CHordat, Jésus devant sa mort (Paris 1970) 91-92.

124. Cfr. M. Dibelius, Die Formgeschichte, 192-193.

125. Cfr. A. VaNHOYE, De narrationibus passionis..., 70-71.

126. Cfr. A. VANHOYE, o. c., 72-73; V. TAYLOR, The Passion Narrative of st. Luke (Cambridge 1972) 77-78. 
como el templo mismo. Va, además, contra la verosimilitud psicológica y natural, pues es dificil imaginar a los miembros del Sanedrín saliendo de sus casas para este asunto bastante entrada la noche. Más lógico es que fueran convocados y acudieran a una reunión de madrugada, al amanecer. Por otra parte, al indicar someramente Mc-Mt la sesión de la mañana de "todo el Sanedrín", sin presentar una declaración en regla, se saca la impresión de que la sesión descrita como tenida durante la noche es idéntica a la narrada en la mañana por Lc e incluso a la que ellos mismos sitúan al alborear el día. Habría entonces en Mc-Mt un desdoblamiento literario de la sesión del Sanedrín, que probablemente puede explicarse por una conjunción y confusión de tradiciones ${ }^{127}$.

Según Jn, Jesús es llevado primeramente a casa del Sumo Sacerdote Anás, ante quien tiene lugar un interrogatorio, acompañado de ultrajes y simultáneo a la primera negación de Pedro. Después de esta comparecencia e interrogatorio, Anás envía a Jesús atado al Sumo Sacerdote Caifás, ante quien debió tener lugar la reunión del Sanedrín en la que Jesús fue condenado a muerte como malhechor y blasfemo ${ }^{128}$. Aquí continúa Pedro negando conocer a Jesús, mientras éste ha dado testimonio público de su doctrina y de si mismo ${ }^{120}$.

¿Cómo, pues, compaginar estas tradiciones evangélicas tan diferentes entre sí? ¿Cuántas sesiones celebró el Sanedrín? ¿Cuántas veces, cuándo y dónde negó Pedro conocer a Jesús? ¿A qué Sumo Sacerdote fue llevado Jesús?

Entre las diversas soluciones a estos interrogantes ha sido bastante aceptada la hipótesis crítico-textual que cambia de lugar Jn 18,24 y lo desplaza al final de Jn 18,13. Con esta modificación, que se encuentra ya en un manuscrito de una antigua versión siríaca y en Cirilo de Alejandría, todo el interrogatorio ocurriría en casa de Caifás, se evita la discrepancia entre Jn y los sinópticos y se reúnen las tres negaciones de Pedro ${ }^{130}$. Tal solución, sin embargo, se funda en una tradición textual prácticamente sin valor, que probablemente corrigió el texto para descartar este enojoso pro-

127. Cfr. P. BENOIT, Pasión y resurrección, 95-96.

128. Aunque In no lo afirma explícitamente, lo supone en 18, 30-32; 19,7.

129. Cfr. J. Schineider, "Zur Komposition von Joh. 18, 12-27. Kaiphas und Annas", en Zeit Neut Wiss 48 (1957) 111-119.

130. Asi, v. gr., M. J. LAGRANGE, Evangile selon st. Jean (Paris 1927) 459462 ; J. SchNeIder, a. c.; R. T. ForTNA, The Gospel of Signs (Cambridge 1970) 117-122. Cfr. A. MaHoney, "A new Look at an old Problem (John 18, 12-14. 1924)", en Cath Bibl Quart 27 (1965) 137-144. 
blema que nos ocupa, y no es demasiado feliz, pues el contenido del interrogatorio en Jn y en los sinópticos es por completo difesente ${ }^{131}$.

Merece especial mención, como más verídica y fundada en el análisis de las diversas tradiciones y redacciones evangélicas, la solución que propone que el orden histórico más probable de los sucesos en esta noche es el presentado por LC y $\mathrm{Jn}{ }^{132}$. De noche tuvo lugar la comparecencia e interrogación ante el Sumo Sacerdote Anás y la negación de Pedro, así como diversos ultrajes y afrentas hacia Jesús por parte de los que le prendieron y custodiaban. Esta interrogación no era oficial o formalmente jurídica, sino privada y sin mayor transcendencia para la evolución del proceso jurídico judio contra Jesús. La tradición de Mc-Mt conservaba un vago recuerdo de esta interrogación nocturna, no haciendo hincapié en dónde había tenido lugar, por lo que inconscientemente trasladó la sesión matutina del Sanedrín al lugar y tiempo de esta comparecencia e interrogatorio de Jesús ante Anás. Nótese, además, que, como se indicó antes, la respuesta de Jesús a Anás en Jn se parece notablemente a la que los sinópticos atribuyen a Jesús en Gethsemani (Mc 14,49; Mt 26,55). Habiendo, pues, puesto ya en boca de Jesús en Gethsemani unas palabras, idénticas esencialmente a las del interrogatorio ante Anás, Mc-Mt han creado un vacío en el relato de lo ocurrido durante la noche en el palacio. Y como la tradición recordaba que había habido un interrogatorio durante la noche, han anticipado la sesión del Sanedrín para llenar ese vacío y satisfacer ese recuerdo.

Tal confusión era tanto más fácil cuanto que, así Anás como Caifás, desempeñaban entonces el oficio de Sumo Sacerdote. Anás, suegro de Caifás, era un hombre de tal influjo que habia conservado el título de Sumo Sacerdote. Hasta puede decirse que él era el Sumo Sacerdote, no de derecho u oficialmente, pero si de hecho. De ahi que Jn le llame absolutamente "el Sumo Sacerdote", mien-

131. Cfr. P. Benott, o. c., 99; A. Dauer, Die Passionsgeschichte, 64-65; R. SCHNACKENBURG, o. c., III, 262.

132. Esta es la opinión, entre otros muchos críticos, de P. BENoIT ("Le procès de Jésus", en Exégèse et Theologie, I, Paris 1961, 265-289; "Jésus devant le Sanhédrin", en Angelicum 20, 1943, 143-165), X. LEON-DuFour ("Passion", en DBS VI, col 1461-63), P. WINTER (The Trial of Jesus, Leiden 1971, 220; "The Marcan Account...", 94-102, donde escribe: "el proceso nocturno ante el Sanedrín en Mc es una creación propia del evangelista..., que refleja una situación derivada de la revuelta del 66 d. C."), D. R. CATCHPOLE, ("The Problem of the Historicity of the Sanedrian Trial", en The Trial of Jesus, London 1970, 47-65), P. Valentin ("Les comparitions de Jésus devant le Sanhédrin", en Rech Scien Relig 59, 1971, 230-236), G. S. SloyaN (Jesus on Trial, Philadelphia 1973, 89-109), etc. 
tras a Caifás le designa como "el Sumo Sacerdote de aquel año" $(18,13)$. El mismo Lc nos proporciona noticias históricas similares, al nombrar en el cargo primero a Anás y luego a Caifás (Lc 3,2 ), como uno más del resto de la familia archisacerdotal (Act 4,6), aunque en este tiempo (= del 18 al $36 \mathrm{~d}$. C.) era éste quien desempeñaba oficialmente el cargo ${ }^{133}$.

La tradición lucana, un tanto posterior a la sinóptica y contemporánea de la juánica, insiste en la acción propiamente jurídica, hecha de madrugada y probablemente en la sede del Sanedrín, en los edificios del templo ${ }^{134}$. Esta fue la de mayor imporiancia y por eso insiste en ella Lc, aunque indirectamente evoca las palabras de Jesús ante Anás, que coloca al final del episodio del prendimiento $(22,53)$.

Según esto, la verdad histórica de lo ocurrido en aquella noche parece favorecer la presentación juánico-lucana. Jesús, arrestado en Gethsemaní, es conducido a casa del Sumo Sacerdote Anás, donde pasa la mayor parte de la noche, aguardando a que el alba de! día siguiente permita la sesión del Sanedrín. Durante esta vigilia Anás y algunos jefes del templo interrogan a Jesús sobre su doctrina y sus discípulos. Este interrogatorio no era oficial, pero la autoridad de Anás da peso a estas pesquisas privadas. Jesús con gran dignidad se niega a contestar abiertamente o calla, por lo que uno de los presentes le afrenta y ultraja, organizándose una rechifla más o menos general.

Al mismo tiempo en el patio Pedro se debate contra los que le asedian a preguntas y llega a negar conocer a su maestro. Se puede admitir también que el interrogatorio ante Anás haya ocurrido en una habitación o sala y que no durara mucho, haciéndole bajar al patio en cuanto se persuade que Jesús no quiere contestar. Allí es donde Jesús, como afirma Lc, pudo mirar a Pedro después de sus negaciones y donde posiblemente fue custodiado durante algún tiempo, hasta ser enviado a Caifás, esto es, ante el Sanedrín, que celebra el proceso jurídico formal contra Jesús de madrugada y donde es condenado como malhechor y blasfemo. Entonces será llevado al procurador romano, Poncio Pilato.

133. Cfr. R. E. Brown, The Gospel acc. to John, II, 820; H. VAN DEN BUSSCHE, o. c., $607-608$.

134. Cfr. J. A. BAILEY, The Tradition common to the Gospels of Luke and John (Leiden 1963) 55-63. 


\section{Jesús ante Anás}

(In 18,13. 19-23)

Esta narración juánica está compuesta a modo de díptico entre Jesús y Pedro. Mientras Pedro, interrogado por una criada, niega conocer a Jesús y ser uno de sus discípulos, Jesús, interrogado por el Pontífice, reconoce que ha dado testimonio público de su doctrina y de sus discípulos ${ }^{135}$.

El evangelista anota que Jesús fue llevado atado (lo repite en el v. 24), en fuerte oposición a la escena del hūerto. Anás, Sumo Sacerdote oficialmente desde el año 6 a. C. al 15 d. C., consiguió mantener su influjo durante largos años, conservando en dicho cargo a un yerno y cinco hijos, todos hechura suya y continuadores de su negocio. El recuerdo amplio sobre Caifás (v. 14) evoca aquella profecia inconsciente $(11,49-52)$, que revela el sentido de la pasión de Jesús ${ }^{136}$.

La interrogación que Anás le dirige es muy diversa de la hecha ante el Sanedrín en los sinópticos. No se trata de su mesianidad, sino sobre sus discípulos y su doctrina. La pregunta podría tener un matiz político (=peligro de sedición), pero sugiere más bien un sentido religioso, como acusando a Jesús de falso profeta por atreverse a hablar en nombre de Dios (=doctrina) y de seducir doctrinalmente a otros (=discípulos). De todos modos conviene notar que los temas y el vocabulario son típicamente juánicos y tienden a presentar a Jesús como el maestro y revelador ${ }^{137}$.

La respuesta de Jesús, presentada enfáticamente en tres partes (yo... yo... yo), insiste también en la presentación de Jesús como revelador (=he hablado... he enseñado... he hablado... he dicho) y en la universalidad de derecho y destino de esta revelación =...ante todo el mundo... siempre... todos los judios... nada a ocultas). Para el evangelista la actividad pública de Jesús ${ }^{138}$ fue una revelación pública (=abiertamente), aunque velada, (cfr. 16, 25), de sí mismo y de su gloria ${ }^{139}$. La presenta aquí como un hecho completo, con valor permanente y universal (primer he hablado,

\footnotetext{
135. Cfr. X. LeON-Dufour, "Passion", 1463.

136. Cfr. R. Bultmann, Johannesevangelium, 497; J. SCHNEIDER, a. c.; $\mathbf{R}$. SChNACKENBURG, o. c., III, 265; A. DAUER, o. c., 72 nota 46.

137. Cfr. M. A. Chevalier, "La comparition de Jésus devant Hanne et devant Caïphe (Jean 18, 12-14 et 19-24)", Neues Testament und Geschichte. Festschrift für O. Cullmann (Tübingen 1972) 179-185.

138. Cfr. In 7-10 especialmente.

139. Cfr. R. BultmanN, o. c., 500.
} 
en perfecto), aunque de hecho en su concretización histórica haya sido hecha solamente a los judíos (restantes verbos en aoristo) en la sinagoga y en el templo, recordados frecuentemente por In al hacer mención del lugar donde Jesús enseña ${ }^{140}$. Así pues, las palabras de Jesús en esta ocasión representan una especie de compendio teológico: Jesús se revela en medio del pueblo y en los centros religiosos de Israel. Tienen muchos contactos con las atribuidas a Jesús por los sinópticos en Gethsemani y responden mejor a su situación, pero están redactadas en el marco de la ideología y configuración juánica.

El Jesús de Jn no calla, como en los sinópticos, pero rehúsa dar una explicación y respuesta directa a la pregunta del Sumo Sacerdote, revelando la razón de ese silencio: ¿Por qué me preguntas? Pregunta a los que me han oido lo que les he hablado; ellos saben lo que he dicho. Para Jn, Anás y los suyos representan al mundo que rechaza a Jesús, condenándose a sí mismo ${ }^{141}$, lo que ilustra el gesto del ministro. De ahi que, frente al representante del judaísmo, Jesús mismo remita a su palabra y revelación anterior, afirmando que nada más tiene que decir ${ }^{142}$.

Inmediatamente después de estas palabras de Jesús, uno de los ministros (guardia o del Sanedrín?) le inflige una bofetada. La escena parece tener un nexo real con las afrentas narradas por los sinópticos en la noche del prendimiento. La bofetada, único ultraje que Jn permite para con Jesús ${ }^{143}$, tiene aquí un matiz de oposición violenta más que de desprecio e irrisión. Simboliza la repulsa hacia Jesús por parte de los judios. La irrisión y la burla no tienen lugar en las narraciones juánicas de la pasión de Jesús, pues es presentada como su exaltación. Del mismo modo la respuesta de Jesús a este ministro dice relación a su doctrina en general, de la que era interrogada: si mi respuesta ha sido impia, perversa, debe mostrarse con testigos; pero si es buena, ¿por qué la rechazáis? El recuerdo de la "prueba" o testigos muestra la incidencia del relato juánico con el de los sinópticos.

La presencia e interrogatorio de Jesús ante Anás aparece así como composición netamente juánica en la que, junto a datos históricos de gran valor, el evangelista insiste en sus temas preferi-

140. Cfr. In 6,$59 ; 7,14.28 ; 8,20$. En los sinópticos Jesús enseña en el monte, en casa, a orilla del mar o desde la barca.

141. Cfr. Jn 9, 39-41.

142. Cfr. H. VAN DEN BUSSChe, o. c., $606 \mathrm{~s}$. 611-614.

143. Cfr. además Jn 19,3. 
$\operatorname{dos}^{144}$. Por lo demás, Jesús, aunque interrogado por el Sumo Sacerdote de los judíos, no aparece ni como reo, ni como condenado, ni como procesado en sentido jurídico formal, sino más bien como su juez. Se da, pues, una inversión de funciones. Por eso Jn ha preferido conservar esta escena y callar el proceso jurídico judío contra Jesús.

\section{La triple negación de Pedro}

(Mc 14,54.66-72; Mt 26,58.69-75; Lc 22,54b-62; Jn 18,15-18.25-27) ${ }^{145}$.

El episodio de la triple negación de Pedro es transmitido por los cuatro evangelistas, normalmente en paralelismo con la narración sobe los avatares de Jesús ante las autoridades judías ${ }^{146}$. Del conjunto de los diversos relatos evangélicos, el episodio puede ordenarse en las siguientes escenas:

Pedro sigue de lejos a Jesús arrestado hasta el palacio del Sumo Sacerdote

(MC 14,54; Mt 26,58; LC 22,54b-55; Jn 18,15-16):

Según los sinópticos, tras el abandono de Jesús por los discipulos, Pedro volvió sobre sus pasos y, generoso e impulsivo como era, aunque miedoso por momentos, le siguió (Mt y Lc escriben le

144. Cfr. A. Dauer, o. c., 82. E. Haenchen ("Historie und Geschichte", 63) y M. A. Chevalier (l. c.), entre otros, sostienen que este episodio es solamente una motivación teológica juánica, sin fondo histórico. Es uno de tantos típicos "encuentros" de Jesús con interlocutores juđíos para presentar a éste como revelador, con la particularidad de que es el último de la serie: con el representante del pueblo. Sobre la insuficiencia de estas afirmaciones, cfr. R. E. BRown, o. c., II 835.

145. Cfr. Ch. Masson, "Le reniement de Pierre. Quelques Aspectes de la formation d'une tradition", en Rev Hist Phil Relig 37 (1957) 24-35; G. KLEIN, "Die Verleugnung des Petrus. Eine traditionsgeschichtliche Untersuchung", en Zeit Theol Kirch 58 (1961) 285-328; E. LINNEMANN, Studien zur Passionsgeschichte, 70108 ; G. W. H. LAMPe, "St. Peter's Denial", en Bull John Ryl Univ Libr Manchester 55 (1972-73) 346-368; R. PEscr "Die Verleugnung des Petrus, Eine Studie zu Mk 14,54. 66-72 (und Mk 14, 26-31)", en Neues Testament und Kirche. Festschrift für R. Schnackenburg (Freiburg 1974) 42-62; K. E. DEWEY, "Peter's Curse and Cursed Peter", en The Passion in Mark. Studies on Mark 14-16 (Philadelphia 1976) $96-114$

146. Cfr. K. E. Dewey, l. c., 109-110; S. Legasse, "Jésus devant le Sanhédrin", en Rev Theol Louv 5 (1974) $172 \mathrm{~s}$. 
seguía, más expresivo) hasta el palacio o casa del Sumo Sacerdote, aunque de lejos. Deseaba ver cómo terminaba aquello (Mt). Pedro entra en el palacio y se sienta con los criados, que se calentaban, sentados alrededor de una hoguera, encendida en medio del patio. La mención del fuego ( $\mathrm{y}$ del frio en $\mathrm{Jn}$ ) responde a la situación concreta, ya que en las noches de primavera el tiempo puede ser bastante frío en Jerusalén ${ }^{147}$.

In ofrece una explicación más detallada del modo cómo Pedro llegó hasta el patio del palacio del Sumo Sacerdote. Junto con Simón Pedro seguía al cortejo, que llevaba preso a Jesús, otro discipulo, conocido del Sumo Sacerdote. Este otro discípulo, que tenía familiaridad con la servidumbre del Pontífice y acceso libre al palacio, entró con el cortejo que llevaba a Jesús en el palacio del Sumo Sacerdote, mientras Pedro se quedaba fuera, junto a la puerta del palacio. El otro discípulo salió y rogó a la portera que permitiera la entrada a Pedro. La antigua versión siríaca escribe "consejo o portero", más normal y elegante, pero sin duda menos real en este caso. La portera accedió a la petición y dejó pasar a Pedro.

Tal explicación es muy verosímil, ya que el arresto de Jesús era todavía secreto y no tenía carácter oficial, de modo que no favorecía los intereses de los que le habian prendido el dejar entrar personas ajenas al escenario de su maquinación. Se aprecian, además, en el relato ciertos detalles, que denotan la presencia de un testigo ocular con gran capacidad de retención ${ }^{118}$.

Negaciones de Pedro

(Mc 14,66-72a; Mt 26, 69-74; Lc 22, 56-60; Jn 18,17-18.25-27).

Con una descripción minuciosa los evangelistas presentan un cuadro histórico en el que se destacan las diversas negaciones de Pedro. Cada relato por separado no presenta dificultad alguna. Pe-

147. Cfr. J. BeRnard, John, II, 598.

148. Cfr. C. H. DoDd, Historical Tradition, 83-88. Sobre la identificación de "este otro discípulo" se ha discutido mucho, así como sobre su identidad con "el discípulo amado", sin llegar a conclusiones convincentes. Sobre el tema cfr. A. KRAGERUD, Der Lieblingsjünger im Johannesevangelium. Ein exegetischer Versuch, Oslo 1951; N. E. Johnson, "The Beloved Disciple in the Fourth Gospel", en Church Quart Rev 167 (1966) 278-291; J. CoLson, L'énigme du disciple, que Jésus aimait, Paris 1969; Th. LoRENzen, Die Lieblingsjünger im Johannesevangelium, Stuttgart 1971; B. DE Solages, "Jean, fils de Zébédée et l'énigme du disciple que Jésus aimait", en Bull Litt Eccl 73 (1972) 41-50; O. CulLMANN, Der johaneische Kreis (Tübingen 1975) 74-88; sobre todo el estudio reciente de F. NEIRYNCK, "The 'other Disciple' in Jn 18, 15-16", en Eph Theol Lov 51 (1975) 113-141 con profusión de opiniones y bibliografía. 
ro si se comparan entre sí, se notan entre ellos tales divergencias, tanto en lo referente a las circunstancias como a los individuos que hacen las preguntas a Pedro, que no se puede soñar con obtener un cuadro perfectamente coherente.

Un repaso general a los diferentes detalles de las negaciones de Pedro muestra que, de computarse todas las negaciones, asi como las diversas personas que las motivan, en vez de tres resultan unas ocho negaciones: dos distintas en la primera, cuatro en la segunda y dos en la tercera ${ }^{149}$. Sin embargo, estas variantes y diferencias son las que podian esperarse de las diferentes transmisiones orales de unos sucesos conocidos a través de la voz pública. Mucho más importante que cualquier intento de reconciliar estos relatos, que manifiestamente quieren destacar con estas tres negaciones el cumplimiento de la profecia de Jesús sobre Pedro ${ }^{150}$, es respetar el contenido de cada evangelio y ver cómo los evangelistas tomaron diversas negaciones de Pedro, hechas en situaciones distintas en esta noche, para encuadrarlas en el esquema tripartito de la profecía de Jesús. De ahí el cuidado en destacar cómo Pedro niega tres veces, teniendo como control cronológico el canto del gaIlo ${ }^{15}$.

La presentación literaria y el punto de vista psicológico de las negaciones de Pedro es diverso en cada evangelista. Mienzras Mc presenta un estilo espontáneo, poco cuidado, y una narración viva, Mt omite las palabras superfluas y da a su narración una progresión más metódica. En ambos, Pedro es presentado al nivel de los guardias o sanedritas, que ultrajan a Jesús, pues su negación sigue a los ultrajes de éstos. Por otra parte, sus negaciones son presentadas con fórmulas violentas en un continuo crescendo hasta el paroxismo del reniego; negación simple, con juramento, con imprecaciones. Se da, además, una oposición entre la postura de Jesús, que públicamente reconoce su mesianidad, y la de Pedro que niega a su maestro ${ }^{152}$.

Lc, por el contrario, con una ordenación más regular en la presentación de los episodios concomitantes, elige un orden descen-

149. Cfr. M. DE TUצA, Del Cenáculo al Calvario, 380-383.

150. Cfr. Mc 14, 30-31; Mt 26, 33-35; Lc 22, 31-34; Jn 13, 36-38.

151. C. H. Mayo sugiere que la señál dada por Jesús no fue el canto del gallo doméstico, muy irregular, sino del "gallicinium" o sonido de trompeta, que se daba al cambio de guardia ("St Peter's Token of the Cock Crow", en Journ Theol stud 22, 1921, 367-370).

152. Cfr. Ch. Masson, l. c.; A. Vanhoye, o. c., 99-100. 
dente en las negaciones, insistiendo menos en la falta del apóstol. Solícito y reverente hacia la persona de Jesús, nunca le designa por su nombre en boca de los adversarios interlocutores, sino sólo mediante el pronombre. Sólo en la conversión de Pedro (v.61) le denomina Señor. Además, el arrepentimiento del apóstol acontece antes de que se hable de los malos tratos infligidos a Jesús por los que le custodiaban, lo que pone de relieve que Pedro, con sus lágrimas, no está al lado de los que insultan a Jesús. Pedro sigue la pasión del Salvador con los sentimientos del pecador convertido, como corresponde a la actitud del discípulo ante un maestro que se humilla hasta lo inverosimil ${ }^{153}$.

La narración juánica es bastante sobria. Como en Lc, todas las negaciones se mantienen en un rotundo no 10 soy, que antitéticamente corresponde a la fórmula "yo soy", aplicada anteriormente a Jesús, cuya respuesta pública ante Anás destaca aún más la negación del discípulo ${ }^{154}$.

\section{Arrepentimiento de Pedro} (Mc 14,72b; Mt 26,75; LC 22, 61-62):

Mc y Mt vinculan literariamente al profetizado canto del gallo el arrepentimiento de Pedro. En Mc al cantar por segunda vez, ya que la primera parece haberle pasado desapercibida. Entonces se recuerda Pedro de la profecía de Jesús y se da cuenta de su pecado: y Pedro se acordó de aquello que le había dicho Jesús: "antes de que cante el gallo ( $\mathrm{Mc}$ añade dos veces), me habrás negado tres veces".

Lc, sin embargo, aún recordando el canto del gallo, vincula literariamente el arrepentimiento de Pedro a una mirada de Jesús: y habiéndose vuelto el Señor, miró a Pedro, y se acordó Pedro de la palabra del Señor, cuando dijo: "antes de que hoy cante el gallo, me habrás negado tres veces". La escena y el gesto del Señor, maravillosamente bellos, son muy importantes desde el punto de vista teológico-parenético e histórico. La mirada penetrante y misericordiosa de Jesús conmueve a Pedro y hace que el discipulo negador cobre aliento para liberarse de aquel lugar y llorar su pecado.

Según Mt-Lc, Pedro, saliendo fuera, lloró amargamente sus ne-

153. Cfr. G. SCHNeIDER, Verleugnung, Verspottung und Verhör Jesu, 73-96, 170-171; A. VANhoye, "Structure et théologie...", 145.

154. Cfr. R. Schnackenburg, o. c., III, 268. 
gaciones. La expresión de Mc es menos precisa, pero más sugestiva: $y$, precipitándose, lloraba. En el fondo las diversas expresiones reflejan con distinto matiz el tremendo dolor y el arrepentimiento de Pedro, que perdurará a lo largo de toda su vida. Esta continuidad del doloroso recuerdo y la penitencia del apóstol son evocados en el cuarto evangelio $(21,15-17)$ con la correspondencia de la triple confesión humilde de Pedro después de la resurrección del Señor. Jn, sin hablar explícitamente de las lágrimas de Pedro, nos brinda la gran lección de humildad aprendida para siempre por el apóstol vehemente en esta noche de la pasión.

\section{Conclusión}

Se puede afirmar con seguridad que el episodio de las negaciones de Pedro es plenamente hisiórico. Por una parte hay dos testigos -Pedro y el otro discípulo - que han asistido a los acontecimientos y han debido relatarlos. Por otra, no se comprende cómo los primitivos cristianos han podido imaginar e inventar semejante escena, tan humillante, degradante y penosa, para Pedro. Afirmar, como han hecho algunos críticos radicales, que el episodio ha sido inventado por resentimiento contra Pedro en un ambiente que le era hostil o para dar cumplimiento a la predicción de Jesús ${ }^{156}$, parece estar fuera de lugar. En el segundo caso sería más fácill y lógico invertir el orden, esto es, concluir que la profecia había sido inventada a raíz de lo sucedido. Pero tanto este episodio como la predicción del mismo tienen todos los visos de la autenticidad histórica ${ }^{157}$.

La lección de las negaciones de Pedro debe engendrar en el cristiano de todos los tiempos gran dosis de temor saludable. Si los primeros cristianos no han dudado en relatar la caída del príncipe de los apóstoles, fue sin duda para ponerse en guardia contra la ex-

156. Así M. Goguer ("Did Peter deny his Lord? A Conjecture", en Harv Theol Rev 25, 1932, 1-27), W. E. BUNDY (Jesus and the first three Gospels, Cambridge, Mass., 1965, 521), E. LiNNEMANN (Studien..., 72-93), G. KLeIN (l. c.), E. LOHNEYer (Das Evangelium nach Markus, Göttingen 1951, 332), M. Wricox ("The Denial-Sequence in Mark 14, 26-31. 66-72", en New Test Stud 17, 1970-71, 426-437), etc.

157. Cfr. J. SchNIEWIND, Das Evangelium nach Markus (Göttingen 1963) 195 ; E. DrNkLeR, "Die Petrus-Rom-Frage", en Theol Rundschau 25 (1959) 199; J. Kosnetter, "Zur Geschichtlichkeit der Verleugnung Petri", en Dienst an der Lehre. Festschrift für Kard. König (Wien 1965) 127-143; H. MERKEL, "Peter's Curse", en The Trial of Jesus. Ed. E. Bambel (London 1970) 65-71; R. ScHNaCKeNBURG, El Evangelio según San Marcos (Barcelona 1973) 296s; R. Pesch, a. c., 58-60. 
cesiva confianza de sí mismos: "el que crea estar seguro, mire no caiga" ${ }^{158}$. Pero al mismo tiempo daban testimonio del llanto o arrepentimiento del apóstol, proclamaban el perdón del Señor y enseñaban que todo pecado, por grande que fuera, podía ser reparado con el llanto del arrepentimiento sincero ${ }^{159}$. En LC especialmente el relato del arrepentimiento de Pedro, suscitado por una mirada del Señor Jesús, que se vuelve hacia él, revela el secreto de toda conversión generosa.

\section{Afrentas y ultrajes contra Jesús}

'Mc 14,65; Mt 26,67; Lc 22, 63-65; Jn 18, 22-23):

Los cuatro evangelistas hablan indistintamente de diversas afrentas y ultrajes recibidos por Jesús en la noche del prendimiento por parte de sus enemigos. Sin embargo, nuevamente se observa en ellos la "concordia discors", ya que, si bien todos los sitúan en esta noche, cada evangelista los describe en un orden diverso y los asigna a personas diferentes. Jn, como se observó, habla solamente de una bofetada, que recibe de un ministro del Pontífice Anás, después del interrogatorio de éste. Los tres sinópticos refieren numerosas afrentas infligidas a Jesús, completándose mutuamente y evocando diferentes aspectos de este misterio de oprobio.

Mc y Mt, al colocar literariamente este episodio a continuación de la sesión del Sanedrín durante la noche y después de la condena sin matices, hacen pensar que fueron los mismos miembros del Sanedrín, sacerdotes, escribas y ancianos, los que cometen estas afrentas. La redacción marciana, al distinguir claramente entre los miembros del Sanedrín (=algunos) y los criados, favorece esta interpretación. Cierto que no es muy artístico imaginar a estos respetables jueces, cualesquiera que fueran sus intenciones para con Jesús, rebajándose hasta tales extremos. Sin embargo, la experiencia muestra que fácilmente se infligen afrentas, ultrajes y hasta tormentos a los prisioneros y acusados, incluso en los mismos procesos juridicos. El relato de Mt ofrece un orden más correcto en los ultrajes ${ }^{160}$, determina lo que Jesús debe adivinar

158. 1 Cor 10,12. Cfr. Rom 11, 20-24; Gal 6,1.

159. Cfr. G. Schille, "Das Leiden des Herrn", en Zeit Theol Kir 52 (1955) 189; J. ERNST, Das Evangelium nach Lukas, 613 ss.; G. SCHNEIDER, o. c., 170.

160. No parece muy lógico escupirle y abofetearle, teniendo la cara tapada, como aparece en Mc. 
(= ¿quién te ha pegado?) y subraya su orientación doctrinal y la dignidad mesiánica de Jesús con la mención del título Cristo.

Lc, que describe los ultrajes en términos más generales y menos ignominiosos, afirma explícitamente que las injurias procedian de los que le tenian preso y consistian más en palabras que en acciones. No se trata, pues, directamente de las autoridades de la nación (aunque el v. 52 daría pie para pensar que había algunos entre ellos), sino de los guardias y criados o ministros, que han arrestado a Jesús en Gethsemaní y le custodian durante la noche. Le tra$\tan$ con frialdad y pasan el tiempo, como suele hacerse en estos casos, jugando con su prisionero. Cierto que la escena es penosa, pero es menos monstruosa y más verosímil que las narradas por Mc-Mt ${ }^{611}$.

En general se puede afirmar que el episodio de los ultrajes y afrentas contra Jesús es plenamente histórico. Lo que se hace con Jesús en esta noche suele ocurrir, si bien en forma menos bruta!, con otros prisioneros... Como aquí se trataba en su mayoría de serviles gentes judias y las acusaciones que pesaban sobre Jesús eran principalmente de orden religioso, se le provoca con mayor razón a adivinar, ya que un profeta debe saberlo todo. De ahi que, en el centro del relato, tal como aparece en los sinópticos, se encuentre el vocablo profeta, aludiendo sin duda a su declaración mesiánica ante el Sanedrín ${ }^{162}$.

Probablemente no es ajena a la mence de los evangelistas la perspectiva teológica de presentar a Jesús como el Siervo de Yahvé, la figura misteriosa, enviado de Dios, que salvará al mundo, a Israel y a los gentiles. Las palabras con que los tres sinópticos describen estas afrentas son muy semejantes a las contenidas en Is 50,6 . Y el recurso y la incorporación del Antiguo Testamento para explicar y describir un episodio neotestamentario es una constante en los hagiógrafos del Nuevo Testamento para mosirar al lector cristiano el cumplimiento y la realización del plan redentor de Dios en las diversas etapas de la historia de la salvación. Esto no quiere decir que los evangelistas hayan inventado los ultrajes y salivazos. El episodio es auténtìcamenĩe histórico, real. De hecho ninguno

161. Cfr. G. SCHNetDER, o. c., 96-104, $171 \mathrm{~s}$; D. L. MULLER, "Playing the Mock Game (Luke 22: 63-64)", en Journ Bibl Lit 90 (1971) 309-313.

162. Cfr. P. BENoIT, "Les outrages à Jésus prophète (Mc XIV, 65 par)", en Neotestamentica et Patristica. Hommage a O. Cullmann (Leiden 1962) 92-110; Pasión y Resurrección, 101-110. 
alude aqui al cumplimiento de esta profecia. Ni siquiera $\mathrm{Mt}$, que lo hace frecuentemente en otras ocasiones menos apropiadas.

En Mt, además, la invocación mesiánica, Cristo, burlesca y sarcásticamente pronunciada por sus adversarios, destaca más claramente las distintas posiciones del antiguo Israel, representado por el Sanedrín, que ultraja a Jesús-Mesías y se burla de él y de la Iglesia o nuevo Israel, que cree en Jesús y le invoca como "Cristo y Señor".

C. MATEOS

Estudio Teológico Agustiniano Valladolid

(Continuará) 